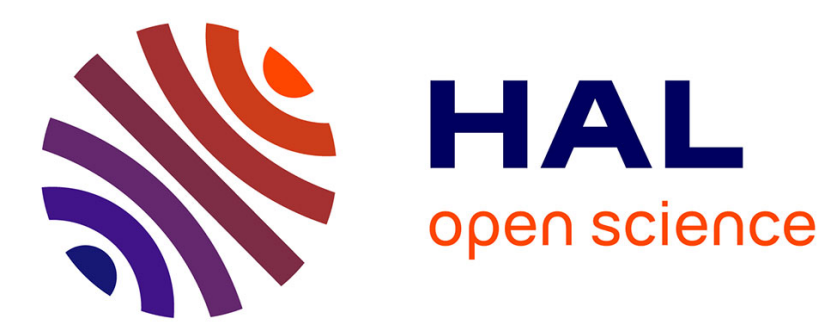

\title{
Diffusion of ionic tracers in the Callovo-Oxfordian clay-rock using the Donnan equilibrium model and the formation factor
}

\author{
D. Jougnot, A. Revil, Philippe Leroy
}

\section{- To cite this version:}

D. Jougnot, A. Revil, Philippe Leroy. Diffusion of ionic tracers in the Callovo-Oxfordian clay-rock using the Donnan equilibrium model and the formation factor. Geochimica et Cosmochimica Acta, 2009, 73 (10), pp.2712-2726. 10.1016/j.gca.2009.01.035 . insu-00447360

HAL Id: insu-00447360

https://hal-insu.archives-ouvertes.fr/insu-00447360

Submitted on 8 Mar 2021

HAL is a multi-disciplinary open access archive for the deposit and dissemination of scientific research documents, whether they are published or not. The documents may come from teaching and research institutions in France or abroad, or from public or private research centers.
L'archive ouverte pluridisciplinaire $\mathbf{H A L}$, est destinée au dépôt et à la diffusion de documents scientifiques de niveau recherche, publiés ou non, émanant des établissements d'enseignement et de recherche français ou étrangers, des laboratoires publics ou privés. 
1 Diffusion of ionic tracers in the Callovo-Oxfordian clay-rock using

2 the Donnan equilibrium model and the electrical formation factor

3

4 D. Jougnot (1, 2, 3), A. Revil (2, 3), and P. Leroy (4)

5

6 1. ANDRA, 1-7 rue Jean Monnet, 92298 Châtenay-Malabry, France

7 2. CNRS-UMR 5559-LGIT, Université de Savoie, Equipe volcan, 73376 Le-Bourget-du-Lac, France

8 3. Colorado School of Mines, Department of Geophysics, Golden, 80401, CO, USA

9 4. BRGM, 3 avenue C. Guillemin, BP 6009, 45061 Orléans, France

10

11

12 Corresponding author:

13 Damien Jougnot

14 Colorado School of Mines, Dept of Geophysics

151500 Illinois street, Golden, CO, 80401.

16 djougnot@mines.edu

17

18

19

20

21

22

23

Intended for publication in Geochimica et Cosmochimica Acta 
The transient diffusion of cationic and anionic tracers through clay-rocks is usually modeled with parameters like porosity, tortuosity (and/or constrictivity), sorption coefficients, and anionic exclusion. Recently, a new pore scale model has been developed by Revil and Linde (2006). This model is based on a volume-averaging approach of the Nernst-Planck equation. In this model, the influence of the electrical diffuse layer is accounted for by a generalized Donnan equilibrium model that is valid for a multicomponent electrolyte. This new model is able to reproduce a number of observations including the determination of the composition of the pore water of the Callovo-Oxfordian argillite, the determination of the osmotic efficiency of bentonite as a function of salinity, the osmotic pressure, and the streaming potential coupling coefficient of clay-rocks. This pore scale model is used here to model the transient diffusion of ionic tracers $\left({ }^{22} \mathrm{Na}^{+},{ }^{36} \mathrm{Cl}^{-}\right.$, and $\left.{ }^{35} \mathrm{SO}_{4}{ }^{2-}\right)$ through the CallovoOxfordian low-porosity argillite. Using experimental data from the literature, we show that all the parameters required to model the flux of ionic tracers (especially the mean electrical potential of the pore space and the formation factor) are in agreement with a previous evaluation of these parameters using totally independent rock properties including the osmotic pressure and HTO diffusion experiments. This confirms that the pore scale model of Revil and Linde (2006) is able to model a high number of transport phenomena into a unified framework. 


\section{INTRODUCTION}

The diffusion of ions in charged porous media like clay materials has been studied by a number of researchers for a variety of geoenvironmental applications including ground water contamination from clay-lined landfills (Malusis and Shackelford, 2003) and the spreading of contaminants from canisters containing nuclear wastes (Chatterji, 2004). The possibility to use clay-rocks as a potential host for the long-term isolation of nuclear wastes has recently driven new researches in this field. The French Nuclear Waste Agency (ANDRA) is presently studying the long-term storage of high-level long-lived nuclear wastes in the Callovo-Oxfordian (Cox) clay-rock formation in the East portion of the Paris basin (ANDRA, 2005). The Cox clay-rock is composed of clay-minerals (between 20 and $50 \%$ in mass fraction), silica, and carbonates. Because of the very low intrinsic permeability of this formation (in the range $10^{-19}$ to $10^{-21} \mathrm{~m}^{2}$, see Escoffier et al., 2000; Gasc-Barbier et al., 2004 ), diffusion of ions is considered to be the major mechanism of the potential spread of ionic species in the bentonite and in the clay-rock formation.

To understand the diffusion of ions in such a complex material, new experiments were performed recently to evaluate the diffusion and the sorption of radio-isotopic elements (Melkior et al. 2004, 2005, 2007; Bazer-Bachi et al. 2005, 2007 and references therein).

However, these authors used phenomenological models and empirical parameters to explain why the diffusion coefficient of some sorbed cationic species (like $\mathrm{Na}^{+}, \mathrm{K}^{+}$, or $\mathrm{Cs}^{+}$) are higher than diffusion coefficient of anions (e.g. chloride). Their approach does not take into account explicitly the influence of the microstructure and electrochemical properties of the mineral/water interface on the diffusivity of ions.

Recently, Appelo and Wersin (2007) used a generalized Donnan equilibrium model to include the effect of the diffuse layer at the mineral/water interface of clay materials upon the diffusivity of ionic species. However, their model does not consider the existence of the Stern 
layer where most of the charged counterions are located (Leroy and Revil, 2004; Leroy et al., 2007, 2008). Their macroscopic transport model is also not explicitly connected to the microscopic phenomena at the mineral/water interface.

In this paper, we are interested to test the approach developed recently by Revil and Linde (2006), Revil (2007), and Leroy et al. (2007). Revil and Linde (2006) and Revil (2007) developed a unifying model of transport properties of water and ions in charged microporous materials. This model is obtained by upscaling the local constitutive equations (Nernst-Planck and Navier-Stokes equations) using a volume-averaging operator. Consequently, the constitutive equations established some simple, and theoretically-based, relationships between the measurable material properties, the key-microstructural parameters of the porous medium (formation factor and intrinsic permeability), and to the electrochemical properties of the double layer coating the clay particles. This model was recently extended to include the effect of partial saturation upon electrokinetic properties (Linde et al., 2007;Revil et al., 2007) and the diffusion of ions in a concentration field for partially saturated media (Revil and Jougnot, 2008). Leroy et al. (2007) have also modeled the composition of the pore water of the Callovo-Oxfordian clay-rock using a extension of this model.

In the present paper, we adapt this modeling approach in order to study the diffusion of radioactive tracers in a clay-rock. After a rapid review of the classical diffusion models used in the literature to interpret such type of data, we will present the microscopic description and underlying assumptions of our tracer diffusion model. This model will be tested against recent experimental data using a variety of 3 radioactive tracers $\left({ }^{22} \mathrm{Na}^{+},{ }^{36} \mathrm{Cl}^{-},{ }^{35} \mathrm{SO}_{4}{ }^{2-}\right)$ on different samples of the Callovo-Oxfordian clay-rock in the porosity range 0.03-0.15. The model will show also a consistency between the mean electrical potential existing in the pore space of the clay-rock and the electrical potential needed to explain the osomotic pressure in the Cox formation. 
The diffusion of ions through a porous material is classically based on the Fick constitutive equation. The flux of the species $i$ through a porous material, $\mathbf{J}_{i}$ (in mol $\mathrm{m}^{-2} \mathrm{~s}^{-1}$ ) is usually described by the first Fick's law,

$$
\mathbf{J}_{i}=-D_{i} \nabla C_{i},
$$

102 where $D_{i}$ is the effective diffusion coefficient in the medium (in $\mathrm{m}^{2} \mathrm{~s}^{-1}$ ) and $C_{i}$ the 103 concentration of species $i$ in the porous medium (in mol $\mathrm{m}^{-3}$ ). The concentrations, usually expressed in $\mathrm{mol} \mathrm{L}^{-1}$, are expressed below in $\mathrm{m}^{-3}$ in the metric system. Several models have 105 been developed to express $D_{i}$ in terms of the textural properties of the porous material (see Bourg et al., 2003, Bourg, 2004 for some phenomenological models and Melkior et al., 2007

107 for a short review of the literature). It is notoriously known that porosity cannot be used alone 108 to determine the diffusion coefficient. Additional fitting parameters, such as tortuosity or 109 constrictivity, have been introduced to account for the fact that only a fraction of the porosity

110 is used by the migration of ions through the pore space or to account for the tortuous path of 111 the ions during their migration through the pore space. One of the most popular models to 112 account for tortuosity was developed by Van Brakel and Heertjes (1974). It yields,

$$
D_{i}=\phi D_{i}^{f} \frac{\delta}{\tau^{2}}
$$

114 where $D_{i}^{f}$ (in $\mathrm{m}^{2} \mathrm{~s}^{-1}$ ) is the self-diffusion coefficient of species $i$ in the bulk pore water, $\phi$ is 115 the porosity, $\tau$ is the tortuosity of the bulk pore space, and $\delta$ is the constrictivity. Further in 116 this paper, we will propose to distinguish two components in the constrictivity parameter: an 
117 geometrical constrictivity $\left(\delta_{g}\right)$ for the pore space topography and an electrostatic constrictivity

$118\left(\delta_{e l}\right)$ for the electrostatic interactions between ions and charged mineral surfaces.

119 The continuity equation for the species $i$, in a porous medium, can be expressed by the 120 second Fick's law:

$$
\phi \frac{\partial C_{i}}{\partial t}+(1-\phi) \rho_{g} \frac{\partial C_{i}^{S}}{\partial t}=-\nabla \cdot \mathbf{J}_{i}
$$

122 with $C_{i}^{S}$ the concentration of ions $i$ that are sorbed onto the mineral surface (in $\mathrm{mol} \mathrm{kg}^{-1}$ ), $\rho_{g}$

123 the grain density (in $\mathrm{kg} \mathrm{m}^{-3}$ ), and $t$ the time (in s). The second term of Eq. (3) corresponds to a 124 source / sink term that is associated with the interactions of the solution with the surface of the 125 minerals. Sorption of solutes in a porous medium can be modeled by simple isotherms (see 126 Limousin et al., 2007 for a recent review) or models accounting for electrical double or triple 127 layer theory (Leroy and Revil, 2004; Leroy et al., 2007). Assuming that the ratio between the 128 sorbed concentration and solution concentration is constant with time, it is customary to 129 introduce a distribution or partitioning coefficient defined by $K_{d}^{i}=C_{i}^{S} / C_{i}$ (in $\left.\mathrm{m}^{3} \mathrm{~kg}^{-1}\right)$ (e.g., 130 Limousin et al., 2007). Using this definition, Eq (3) can be written as follow:

$$
\left[\phi+(1-\phi) \rho_{g} K_{d}^{i}\right] \frac{\partial C_{i}}{\partial t}=-\nabla \cdot \mathbf{J}_{i}
$$

132 Introducing the effective sorption and the first Fick's law in Eq. (4) yields the classical 133 diffusion equation in this equation,

$$
\frac{\partial C_{i}}{\partial t}=\nabla \cdot\left(\eta_{i} \nabla C_{i}\right)
$$

where $\eta_{i}$, the apparent diffusivity of ion $i$, is defined by,

$$
\eta_{i}=\frac{D_{i}}{\left[\phi+(1-\phi) \rho_{g} K_{d}^{i}\right]}
$$

137 Note that in this paper, we use the expression "diffusion coefficient" to describe the material 138 properties arising in first Fick law (which is the constitutive equation) and the term 
139 "diffusivity" to describe the material properties arising in the diffusion equation obtained by

140 combining the first and second Fick's law. If sorption can be neglected for a given tracer, the

141 diffusivity of this tracer is equal to the ratio between the effective diffusion coefficient and the

142 porosity $\eta_{i}=D_{i} / \phi$ (Revil and Leroy, 2004; Revil et al., 2005).

143 The previous model is however too simplistic. It does not account for the 144 concentrations of the ionic species in the micropores because of the existence of the electrical

145 diffuse layer. To account for this effect, Muurinen et al. (1988) proposed the introduction of 146 an effective porosity $\phi_{\text {eff }}$ in the mass conservation equation. This yields:

$$
\phi_{e f f_{i}} \frac{\partial C_{i}}{\partial t}=\nabla \cdot\left(\frac{\phi_{\text {eff }} D_{i}^{f}}{\tau^{2}} \nabla C_{i}\right) .
$$

148 For anions, this effective porosity can also be modeled by using a negative value of the 149 distribution coefficient. This very popular approach is however phenomenological in nature 150 and $\phi_{\text {eff }}$ is a fitting parameter that takes different values for different ions.

Bourg (2004) proposed a diffusion model in bentonite. This model divides the medium

152 in three parallel pore networks: a macroporous one and two microporous (a two-layer and a 153 three-layer water molecule in clay's interlayer). Each pore diffusion is described with a 154 tortuosity $\tau$ (purely geometrical) and a constrictivity $\delta$ (which take into account pore section 155 variability, steric effect, viscosity effect). He considered the same tortuosity for the three 156 networks. The total diffusion flux is the sum of the fluxes for each pore network.

157 Other authors consider the division of the connected porosity into compartments: one 158 for the sorbed species and the bulk water. According to Kim et al. (1993) and Eriksen at al. 159 (1999), these two compartments contain mobile charges. Therefore two diffusion coefficients 160 have to be considered: the bulk diffusion coefficient $D_{i}$ and the surface diffusion coefficient 
$161 D_{i}^{S}$ (in $\mathrm{m}^{2} \mathrm{~s}^{-1}$ ). Introducing this surface diffusion coefficient in the constitutive equation 162 yields,

163

164

$$
\mathbf{J}_{i}=-\left[D_{i}+(1-\phi) \rho_{g} K_{d}^{i} D_{i}^{S}\right\rfloor \nabla C_{i}
$$

This model was used by Muurinen (1994) to model the diffusion of cations in charged porous media. He found that $D_{i}$ is generally stronger than $D_{i}^{S}$ by at least one order of magnitude. This result is consistent with the fact that the electromigration mobility of the counterions in the Stern layer is usually smaller than the mobility of the ions in the bulk pore water by one order of magnitude (Revil et al., 1998; Revil, 1999). However, there is no reason that surface diffusion would act in parallel to the bulk diffusion. We know, from electrical conductivity models, that the electromigration of the ions follows very different paths between the bulk pore space and the surface of the pores (Bernabé and Revil, 1995). In addition, there is no clear picture of surface diffusion in the Stern layer. Models for the electromigration of the counterions in the Stern layer predict no migration of the counterions in this layer at zero frequency (Leroy et al., 2008). Because of the intrinsic connection between diffusion and electromigration, this implies that the diffusion of the counterions in the Stern layer is physically not possible because it is not possible to build surfaces concentration gradients in the Stern Layer. In addition, the fraction of counterions between the Stern Layer and the diffuse layer is relatively independent on the salinity of the pore water (see Leroy and Revil, 2004).

The main problem with the previous approaches is that they do not take in consideration the influence of the electrical diffuse layer upon the concentrations of the ionic species in the micropores (see Leroy et al., 2007). Some diffusion models, however, are partially based on the properties of the electrical double layer. Several authors proposed to divide the pore space into three compartments (i) the Stern layer with immobile sorbed ions, (ii) the diffuse layer with mobile ions (but with concentrations determined by solving the 
187 Poisson-Boltzmann differential equation), and (iii) the bulk water of the pore which contains

188 free ions. Sato et al. (1995) proposed for example to introduce the contribution of ion located 189 in the diffuse double layer with an electrostatic constrictivity $\delta_{e l}$ :

$$
\mathbf{J}_{i}=-\delta_{e l} D_{i} \nabla C_{i}
$$

This electrostatic constrictivity is the ratio between the average concentration of ion in the diffuse layer $C_{i}^{d}(x)$ and the concentration in the bulk water $C_{i}$ (Sato et al., 1995),

$$
\delta_{e l}=\frac{1}{R C_{i}} \int_{0}^{R} C_{i}^{d}(x) d x
$$

194

where $R$ is the mean pore radius, $x$ is the distance normal to the surface of the pores, and $C_{i}^{d}(x)$ is the local concentration of species $i$ determined by solving the Poisson-Boltzmann equation at the interface solution scale (local scale). Ochs et al. (2001) used however electrostatic constrictivity as a fitting parameter. We will show in Section 3 that our approach yields a much better expression to determine the electrostatic constrictivity, which will be based on an extension of Donnan equilibrium theory.

Molera and Eriksen (2002) use a partition coefficient $f$ between the species located in the diffuse-layer and those located in the Stern layer. This fraction is assumed to have no dependence with $C_{i}$ and $C_{i}^{S}$. This yields another expression for the constitutive equation,

$$
\mathbf{J}_{i}=-\left\{D_{i}\left[1+f \frac{(1-\phi)}{\phi} \rho_{g} K_{d}^{i}\right]\right\} \nabla C_{i}
$$

However, they do not provide a way to estimate this parameter from the underlying electrical double layer theory.

In all the models discussed previously, the parameters involved in the generalized Fick's law (like the electrostatic constrictivity $\delta$ or the coefficient $f$ ) have to be determined empirically. In the next section, we use a ionic diffusion model based on a volume averaging approach of the Nernst-Planck equation and related to the electrical double layer theory (Revil 
210

211

212

213

214

215

216

217

218

219

220

221

222

223

224

225

226

227

228

229

230 231 particles. This charge density includes the charge density due to the active sites covering its

232 surface $Q_{0}$ and the charge density of the Stern Layer $Q_{\beta}$ (Figure 2), $S$ (in $\mathrm{m}^{2}$ ) is the surface 233 area of the interface separating the solid and the liquid phases in a representative elementary

and Linde, 2006). We start with the work of Leroy et al. (2007) who modeled the pore water composition of the Callovo-Oxfordian argillite (COx) accounting for the micro- and macroporosity. We extend their work to the modeling of the diffusion of ionic tracers through clay-rocks. This model will be used to interpret the experimental results obtained by Melkior et al. (2007) and Bazer-Bachi et al. (2007) who characterize the diffusion of alkaline cations and anions through Callovo-Oxfordian argillite core samples.

\section{A NEW MODEL}

\subsection{Underlying Assumptions}

In this section,w e develop a model for the Cox clay-rock (see Figure 1). We consider a charged porous medium fully saturated by a multicomponent electrolyte with $Q$ species. In contact with water, this surface of the solid phase of the clay particles is assumed to carry a net electrical charge density because of the complexation of the surface sites with the elements of the pore water and isomorphic substitution in the crystalline framework. This surface charge density is responsible for the formation of an electrical triple layer (Figure 2) that includes the Stern layer and the diffuse layer (Hunter, 1981).

The electroneutrality of a representative elementary volume of the rock is written as:

$$
\bar{Q}_{V}+\frac{S}{V_{f}} Q_{S}=0
$$

where $\bar{Q}_{V}$ is the total charge of the diffuse layer per unit pore volume of the connected porosity, $Q_{S}=Q_{0}+Q_{\beta}$ is the total surface charge density (in $\mathrm{C} \mathrm{m}^{-2}$ ) on the surface of the clay 
234 volume of the material, and $V_{f}$ is the pore volume (in $\mathrm{m}^{3}$ ) of the same representative

235 elementary volume. The volumetric charge density $\bar{Q}_{V}$ corresponds to the net amount of

236 charge of the diffuse layer per unit pore volume (in $\mathrm{C} \mathrm{m}^{-3}$ ). It is defined by:

$$
\bar{Q}_{V}=\left(1-f_{Q}\right) Q_{V},
$$

where $f_{Q}$ is the fraction of charge carried by the counterions located in the Stern layer or, in other words, the partition coefficient of the countercharge between the Stern and the diffuse layers, and $Q_{V}$ represents the total charge density associated with the cation exchange capacity of the material (Revil et al., 2002)

$$
Q_{V}=\rho_{g}\left(\frac{1-\phi}{\phi}\right) \mathrm{CEC},
$$

where $\rho_{g}$ the solid grain density (in $\mathrm{kg} \mathrm{m}^{-3}$ ) and the CEC is the cation exchange capacity of

244 the medium (in mol $\mathrm{kg}^{-1}$ ). Using an electrical triple layer model, Leroy et al. (2007) obtained $245 f_{Q}=0.94 \pm 0.02$ at $25^{\circ} \mathrm{C}$ for the COx clay-rock. Gonçalvès et al. (2007) obtained $f_{Q} \propto 0.85$

246 from filtration efficiency experimental data for a compacted bentonite. This means that a large

247 fraction of the counterions are located in the Stern layer.

248 In thermodynamic equilibrium, the Donnan equilibrium model is based on the equality 249 between the electrochemical potential of the ions in the pore space of the charged porous 250 material and in a reservoir of ions in contact with the charged porous material. In terms of 251 concentrations, the concentration of the species $\mathrm{i}$ in the pore space of the material, $\bar{C}_{i}$, is 252 related to the concentration of the species I in the reservoir, $C_{i}$, by (e.g., Revil and Linde, 253 2006)

$$
\bar{C}_{i}=C_{i} \frac{\gamma_{i}}{\bar{\gamma}_{i}} \exp \left(-\frac{q_{i} \varphi_{m}}{k_{B} T}\right),
$$


255 where $q_{i}=( \pm e) z_{i}$ represents the charge of the ion $i$ (in C) with $z_{i}$ the valence of the ion and $e$

256 the elementary charge $\left(1.6 \times 10^{-19} \mathrm{C}\right), k_{B}$ the Boltzmann constant $\left(1.381 \times 10^{-23} \mathrm{~J} \mathrm{~K}^{-1}\right), T$ the 257 absolute temperature in $\mathrm{K}, \gamma_{i}$ and $\bar{\gamma}_{i}$ are the activity coefficients of ion $i$ in the macropores 258 and micropores, respectively, the ionic concentration in micropores, and $\varphi_{m}$ is the mean 259 electrical potential in the pore space of the medium. Leroy et al. (2007) showed that the ration 260 of the activity coefficient can be neglected $\left(\gamma_{i} / \bar{\gamma}_{i} \approx 1\right)$.

261 The potential $\varphi_{m}$ can be determined from the volumetric charge density $\bar{Q}_{V}$ by 262 solving numerically the following charge balance equation (see Revil and Linde, 2006; Leroy 263 et al., 2007),

$$
\bar{Q}_{V}=\sum_{i=1}^{Q} q_{i} C_{i} \exp \left(-\frac{q_{i} \varphi_{m}}{k_{B} T}\right)
$$

265 To perform these computations, we need the macropore water composition proposed for 266 example by the THERMOAR model (Gaucher et al., 2004) at $25^{\circ} \mathrm{C}$. Following Leroy et al. 267 (2007), we took $\mathrm{CEC}=0.18 \mathrm{~mol} \mathrm{~kg}^{-1}, \quad \rho_{g}=2700 \mathrm{~kg} \mathrm{~m}^{-3}, \quad T=298.15 \mathrm{~K} \quad\left(25^{\circ} \mathrm{C}\right), \quad$ and $268 f_{Q}=0.94 \pm 0.02$. With these parameters, we will show later that the mean electrical potential 269 of the pore space of the Cox clay-rock is typically in the range from $-20 \mathrm{mV}$ to $-40 \mathrm{mV}$.

270 From Eqs. (10) and (15) and using $\gamma_{i} / \bar{\gamma}_{i} \approx 1$, the mean electrical potential can be also 271 related to the electrostatic constrictivity introduced by Sato et al. (1995) (see section 2):

$$
\delta_{e l}=\frac{\bar{C}_{i}}{C_{i}}=\exp \left(-\frac{q_{i} \varphi_{m}}{k_{B} T}\right) .
$$

For the COx clay-rock, surface properties are dominated by the reactivity and specific 274 surface area of smectite. Using the triple layer model, we can determine the distribution 275 coefficient $K_{d}^{i}=C_{i}^{S} / C_{i}$ using the calculated surface site density of sorbed counter-ions in the 276 Stern layer $\Gamma_{\mathrm{X} i}^{0}$ (in sites $\mathrm{m}^{-2}$ ). The subscript "X" refers to the surface sites resulting from 
277 isomorphic substitutions into the mineral lattice and situated on the basal planes of the

278 smectite particles (Leroy et al., 2007). In most of experimental studies, the distribution

279 coefficient $K_{d}^{i}$ is obtained by batch or column experiment for each type of tracer.

280 The concentration of sorbed species $C_{\mathrm{i}}^{S}$ is given by:

$$
C_{i}^{S}=\Gamma_{\mathrm{X} i}^{0} S_{s p}
$$

282 where $S_{s p}$ is the specific surface (in $\mathrm{m}^{2} \mathrm{~kg}^{-1}$ of mineral). Gaucher et al. (2004) proposed an

283 average specific surface for the COx: $S_{s p}=5 \times 10^{4} \mathrm{~m}^{2} \mathrm{~kg}^{-1}$. In the case respectively of 284 monovalent and bivalent counterions, the surface site density of sorbed counterions in the 285 Stern layer $\Gamma_{\mathrm{X} i}^{0}$ is determined by Leroy et al. (2007):

$$
\begin{aligned}
\Gamma_{\mathrm{X} i}^{0} & =\frac{\Gamma_{\mathrm{X}}^{0} a_{i}}{K_{i}} \exp \left(-\frac{e \varphi_{\beta}}{k_{B} T}\right), \\
\Gamma_{\mathrm{X} i}^{0} & =\frac{\Gamma_{\mathrm{X}}^{0^{2}} a_{i}}{-2 K_{i} \frac{Q_{0}}{e}} \exp \left(-\frac{2 e \varphi_{\beta}}{k_{B} T}\right),
\end{aligned}
$$

where $\varphi_{\beta}$ is the electrical potential at the Stern plane and $\Gamma_{\mathrm{X}}^{0}$ the surface site density of the "X" sites. Leroy et al. (2007) have determined an average of these two parameters for the COx medium: $\varphi_{\beta}=-95.3 \mathrm{mV}, \Gamma_{\mathrm{X}}^{0}=9.1 \times 10^{16}$ sites $\mathrm{m}^{-2}$. The parameter $a_{i}$ is the activity of the species $i$ in the macropores, $Q_{0}$ (in $\mathrm{C} \mathrm{m}^{-2}$ ) the surface charge density at the surface of mineral, and $K_{i}$ the speciation constants associated with the adsorption/desorption of the counterion $i$. This model will be used to compute a priori value for $K_{d}^{N a}$ of the ${ }^{22} \mathrm{Na}^{+}$tracer in section 5 .

\subsection{A Model for the Diffusion of Tracers}


299 its electrochemical potential. In the present case, there is no macroscopic electrical field

300 because of the concentration of the tracer is much smaller than the ionic strength of the pore

301 water. In appendix A, we show that this model yields an apparent Fick's law,

$$
\begin{gathered}
\mathbf{J}_{i}=-D_{i} \nabla C_{i}, \\
D_{i}=\frac{\beta_{i} \bar{C}_{i} k_{B} T}{q_{i} C_{i} F},
\end{gathered}
$$

304

305

306

307

308

309

310

311

312

313

314

315

316

317

where $D_{i}$ is the effective diffusion coefficient of the ionic species in the microporous charged medium, $\beta_{i}$ is the ionic mobility, and $F$ is the electrical formation factor. Note that $D_{i}$ is the product of three terms: (i) the self-diffusion of the ionic tracer in the water $D_{i}^{f}$, which is expressed by the Nernst-Einstein relation,

$$
D_{i}^{f}=\frac{\beta_{i} k_{B} T}{q_{i}}
$$

(ii) the electrical formation factor $F$ which can be related to the porosity by Archie's law $F=\phi^{-m}$ (Archie, 1942), where $m$ is called the cementation exponent and with $1 \leq m \leq 3$ for most of all media ( $m$ has been determined equal to $1.95 \pm 0.04$ in the COx by Revil et al., 2005; and comprises between 2 and 3 by Descostes et al., 2008), and (iii) the $\bar{C}_{i} / C_{i}$ ratio, which is given by Eq. (15).

From Eqs. (15), (22), and (23), we obtain the following relationship between the effective diffusion coefficient and the diffusivity:

$$
\begin{gathered}
\eta_{i}=\frac{D_{i}^{f}}{\phi+(1-\phi) \rho_{g} K_{d}^{i}}\left(\frac{1}{F}\right) \exp \left(-\frac{q_{i} \varphi_{m}}{k_{B} T}\right) . \\
D_{i}=\frac{D_{i}^{f}}{F} \exp \left(-\frac{q_{i} \varphi_{m}}{k_{B} T}\right) .
\end{gathered}
$$

Therefore the diffusivity of an ionic tracer depends only upon three key-parameters: $K_{d}^{i}, F$, and $\varphi_{m}$. The formation factor can be obtained by a variety of methods like the measurement 
320 of the electrical conductivity of the porous material at different salinities of the brine to

321 separate the contribution from the brine conductivity from the surface conductivity

322 contribution (note that $F$ is NOT the ratio of the brine conductivity to the effective

323 conductivity of the rock as written in a number of papers). The formation factor can also be

324 obtained by steady-state HTO (tritiated water) diffusion experiments. HTO is considered to be

325 a non-reactive species with the mineral/water interface. Therefore the model of Revil (1999)

326 yields $F=D_{\text {HTO }}^{f} / D_{\text {HтO }}$ where $D_{\text {HTO }}^{f}$ is the value of self-diffusion coefficient of HTO in water

327 and $D_{\text {HTO }}$ represents the value of the effective diffusion coefficient of HTO through the 328 porous material.

\section{NUEMRICAL SIMULATIONS AND SENSITIVITY ANALYSIS}

331

The previous system of equations was solved by a PDE solver based on the finiteelement method (the Earth Science module of COMSOL Multiphysics ${ }^{\mathrm{TM}}$ 3.4). We have checked the accuracy of the solver by comparing the results with known analytical solutions (e.g. Crank, 1975). The problem can therefore be solved in 1D, 2D, or 3D accounting for the heterogeneity in the distribution of the material properties (e.g., the formation factor) or the physicochemical parameters associated with the clay content and the clay mineralogy.

To keep our numerical test simple in this paper (and to compare our model to experimental data), we consider the $1 \mathrm{D}$ problem of a tracer through-diffusion experiment. The through diffusion technique is common laboratory method to determine the diffusion properties of consolidated clay material (e.g., Melkior et al., 2004). A small cylinder of the medium is placed between two reservoirs filled with water in chemical equilibrium with this medium. In order to study diffusion properties of a considered ionic species $i$, a trace concentration of a radioactive isotope is placed in the upstream reservoir. As the tracer 
345 concentration is very low, there is no real concentration gradient in the medium and therefore

346 no electroosmosic flow and no macroscopic electrical field. Tracer concentrations in each

347 reservoir are managed and kept as constant as possible: trace concentration in the upstream

348 reservoir and null in the downstream reservoir. In general, diffusion properties of medium are

349 determined by tracer influx in the downstream reservoir (Melkior, 2000 and Melkior et al., 350 2004). We use constant boundary conditions: $C_{T}=10^{-14} \mathrm{~mol} \mathrm{~m}^{-3}$ (trace level) in the upstream 351 reservoir and $C_{T}=0 \mathrm{~mol} \mathrm{~m}^{-3}$ in the downstream reservoir (Figure 3). We note $L$ (in $\mathrm{m}$ ) the 352 length of the core sample, which is divided into 120 elements.

353 We compute the evolution of normalized ionic fluxes $\mathbf{J}_{\mathrm{N}}$ in the downstream reservoir 354 as a function of time. The flux of the ionic tracer in the downstream reservoir is normalized by 355 the tracer concentration in the upstream reservoir and by the length $L$ of the core sample. Thus 356 the normalized flux $\mathbf{J}_{\mathrm{N}}$ is expressed in $\mathrm{m}^{2} \mathrm{~s}^{-1}$. Time axis will be expressed in days for 357 convenience (the computations are all performed in SI units).

358 We discuss now the sensitivity of the model to its parameters described in section 3.

359 This synthetic case was implemented with the properties of the COx and the pore water 360 chemistry obtained by Leroy et al. (2007). The porosity $\phi=0.164$ yields $F=\phi^{-1.95}=34.0$.

361 The density $\rho_{g}=2700 \mathrm{~kg} \mathrm{~m}^{-3}$, the $\mathrm{CEC}=0.18 \mathrm{~mol} \mathrm{~kg}^{-1}$, and the partition coefficient $f_{Q}=0.94$

362 yield $\varphi_{m}=-14.9 \mathrm{mV}$ using Eqs. (13)-(16). If the partition coefficient $f_{Q}$ takes the values 0.92

363 and $0.96, \varphi_{m}$ is equal to -18 and $-11 \mathrm{mV}$, respectively. We consider a radioactive metal cation

364 tracer $\mathrm{M}^{+}$with a total concentration (tracer and stable isotope) in the medium $365 C_{\mathrm{M}^{+}}=31.5 \times 10^{-3} \mathrm{~mol} \mathrm{~L}^{-1}$, the mobility $\beta_{\mathrm{M}^{+}}=5.19 \times 10^{-8} \mathrm{~m}^{2} \mathrm{~s}^{-1} \mathrm{~V}^{-1}$ and the following 366 distribution coefficient $K_{d}^{\mathrm{M}^{+}}=10^{-3} \mathrm{~m}^{3} \mathrm{~kg}^{-1}$. Figure 4 shows the sensitivity of the model to 367 these four important parameters. 
By definition (see section 3), the formation factor $F$ and the electrical mean potential $\varphi_{m}$ (which depends on $f_{Q}$ ) influence the effective diffusion coefficient, while the distribution 370 coefficient $K_{d}$ affects only the apparent diffusion coefficient. Figure 4a, 4b, 4c and 4d show

371 the sensitivity of the model to $F, \varphi_{m}, f_{Q}$, and $K_{d}$ respectively. The model is very sensitive to 372 these parameters. Lower is the formation factor $F$, higher is the diffusion flux. The parameters 373 $\varphi_{m}$ and $f_{Q}$ are related to each other. For a cation, lower is the mean electrical potential $\varphi_{m}$, higher is the normalized flux.

\section{COMPARISON WITH EXPERIMENTAL DATA}

\subsection{Laboratory Experiments}

The model presented in Section 4 is compared to tracer through-diffusion experiments in Callovo-Oxfordian clay-rock samples. We consider the following tracers (i) ${ }^{22} \mathrm{Na}^{+}$(data from Melkior et al., 2007), (ii) ${ }^{36} \mathrm{Cl}^{-}$, and (iii) ${ }^{35} \mathrm{SO}_{4}{ }^{2-}$ (data from Bazer-Bachi et al., 2007). The core samples used by these authors have been extracted from different locations in the COx formation. The properties of the core samples are summarized in Table 1. The samples from K100 in Bazer-Bachi et al. (2007) corresponds toa end-member of the overall formation in term of clay content and porosity (see Table 1).

Through-diffusion experiments were performed in two different core samples for ${ }^{36} \mathrm{Cl}^{-}$ and ${ }^{35} \mathrm{SO}_{4}{ }^{2-}$. This could explain the small differences in porosities and formation factors for the two experiments. Experiments were run with a synthetic water of a composition as close as it possible to the chemical equilibrium with the initial medium (see Table 2). Samples were put in contact with this synthetic water for several weeks to reach equilibrium. Diffusion results are presented as normalized ionic out-flux $\mathrm{J}_{N}$ measured in the downstream reservoir 
392 versus time. This allows the comparison between results for different values of the thickness

393 and the diameter of the samples.

394 In order to compare the model with the experimental data, we fisrt determine a prior 395 values for the three key-paraemetrs (the formation factor, the mean electrical potential of the 396 pore space, and the sorption coefffficients). For each sample, HTO diffusion data are used to 397 determine the a priori value of the formation factor using $F=D_{\text {HTO }}^{f} / D_{\text {HTO }}$. Results are given 398 in Table 3. Then, from the synthetic porewater composition and the model described in 399 section 3.1, we determine the a priori, value of the mean electrical potential $\varphi_{m}$ (see Eqs 13 to 400 16). They are given in Table 3 using the value $f_{Q}=0.94$ discussed above. We use the 401 distribution coefficients $K_{d}^{i}$ given by Melkior et al. (2007) and Bazer-Bachi et al. (2007) for 402 each sample. These distribution coefficients have been determined by batch test or column 403 test experiments. The a prior values of the distribution coefficient of cations (counterions) can 404 also be obtained from Eq. (18) to (20). Therefore, we will compare this result for ${ }^{22} \mathrm{Na}^{+}$in the 405 sample HTM102 (-464 m deep), to the $K_{d}$ value obtained by batch experiment from Melkior 406 et al. (2007).

407 For each data set, we fit the data with the Simplex algorithm (Caceci and Cacheris, 408 1984) to obtain the a posterior values of the key-parameters $F, \varphi_{m}$, and $K_{d}^{i}$. The forward 409 problem solved by COMSOL Multiphysics ${ }^{\mathrm{TM}} 3.4$ is coupled to an optimization routine 410 written in $\mathrm{MatLab}^{\circledR}$ routine (Figure 5). Our algorithm looks for the minimum of the cost 411 function $G$,

$$
\begin{aligned}
& \operatorname{Min} G \equiv \sum_{i=1}^{N}\left|\frac{\mathbf{J}_{\mathbf{N} \text { Exp }}^{i}-\mathbf{J}_{\mathbf{N} \text { Model }}^{i}}{\mathbf{J}_{\mathbf{N} \text { Model }}^{i}}\right|+2 / 3 R, \\
& R \equiv\left|\frac{F^{o p t}-F^{a p}}{F^{a p}}\right|+\left|\frac{\varphi_{m}^{o p t}-\varphi_{m}^{a p}}{\varphi_{m}^{a p}}\right|+\left|\frac{K_{d}^{o p t}-K_{d}^{a p}}{K_{d}^{a p}}\right|
\end{aligned}
$$


414 where $N$ is the number of the experimental data $i$, and $R$ a regularization term (see Tikhonov, 415 1963). The superscripts “opt" and "ap" mean optimized and a priori parameters, respectively. 416 Figure 6 shows that the cost function $G$ has an unique minimum.

417 Figure 7 presents fitted formation factors of the investigated samples versus the 418 porosity. We have also plotted $F$ from bibliographic data on the Callovo-Oxfordian and 419 Archie's law $F=\phi^{-m}$ (for $m=1.95$ and $m=3$ ) on this figure to show the consistency of the 420 fitted values. We notice that $m=3$ correspond to the proposed value of Mendelson and Cohen 421 (1982) for long smectite minerals, like montmorillonite. Note that these formation factors 422 results also from different evaluations: Revil et al. (2005) obtained their formation factors 423 (Figure 7a) from electrical conductivity measurement at different salinities while the values 424 proposed by Descostes et al. (2008) are based on HTO diffusion data (Figure 7b).

425 Figure 8 shows the fitted mean electrical potential versus porosity compared to the 426 model of Revil and Linde (2006) described in Eqs. (13)-(16), using the porewater chemistry 427 given by the bibliography (Table 2).

428 The distribution coefficient $K_{d}^{N a}$ studied by Melkior et al. (2007) can be calculated 429 following our approach by Eq. (18)-(20) and use as an a priori parameter. This computation 430 use COx parameters: $\varphi_{\beta}=-95.3 \times 10^{-3} \mathrm{~V}, \Gamma_{\mathrm{x}}^{0}=9.1 \times 10^{16}$ sites $\mathrm{m}^{-2}$ (from Leroy et al., 2007), 431 and $S_{s p}=5 \times 10^{4} \mathrm{~m}^{2} \mathrm{~kg}^{-1}$ (from Gaucher et al., 2004). Leroy at al. (2007) have also determine $432 K_{N a}=0.80 \pm 0.05$, which is consistent with the value proposed by Avena and De Pauli (1998) $433\left(K_{N a}=0.77\right)$. Using the pore water composition proposed by Melkior et al. (2007) $434\left(C_{\mathrm{Na}^{+}}=3.44 \times 10^{-3} \mathrm{~mol} \mathrm{~L}^{-1}\right)$, Eq. (19) yields the surface site density of counterions in the Stern 435 layer equal to $\Gamma_{\mathrm{XNa}}^{0}=1.72 \times 10^{17}$ sites $^{-2}$. 
We ran an optimization for the ${ }^{22} \mathrm{Na}^{+}$tracer diffusion data for sample HTM102 (464 m 440 deep) (Melkior et al., 2007). The value of the distribution coefficient they found by a batch 441 experiment is equal to $0.41 \times 10^{-3} \mathrm{~m}^{3} \mathrm{~kg}^{-1}$. And using the TLM model of Leroy et al. (2007), 442 we determine an a priori value of $K_{d}^{N a^{+}}=0.414 \times 10^{-3} \mathrm{~m}^{3} \mathrm{~kg}^{-1}$ which corresponds to an 443 excellent agreement between the TLM model and the experimental value by a batch 444 experiment. A priori values for the formation factor and the mean electrical potential are $445 F=89.6$ and $\varphi_{m}=-23.2 \mathrm{mV}$, respectively.

446 The fitted normalized flux curve and experimental data are presented in Figure 9. The 447 best fit yields the following a posteriori values: $F=82.6, \varphi_{m}=-23.5 \mathrm{mV}$, and $K_{d}=0.704 \times 10^{-}$ $448{ }^{3} \mathrm{~m}^{3} \mathrm{~kg}^{-1}$. The correlation coefficient between the fitted model and experimental data is very 449 good $\left(\mathrm{R}^{2}=97.4 \%\right)$. The fitted and the computed formation factor $F$ are very close $450(R E=7.9 \%)$. The mean electrical potential fitted corresponds pretty well to the computed one $451(R E=2.6 \%)$. But the distribution coefficient presents a difference but is still acceptable $452(R E=41.8 \%)$. The differences seen between fitted and computed parameters can easily be 453 explained by both the uncertainties on the experimental data, the porosity, and the value of $F$ 454 resulting from HTO diffusion data.

\subsubsection{Diffusion of ${ }^{36} \mathrm{Cl}^{-}$}

We ran the simulation for ${ }^{36} \mathrm{Cl}^{-}$tracer diffusion in the EST205 K100. Figure 10 shows 459 the confrontation between the fitted normalized diffusion flux following our model and 460 experimental data from Bazer-Bachi et al (2007). The chloride ${ }^{36} \mathrm{Cl}^{-}$is a non-sorbed tracer, so 461 we consider $K_{d}=0 \mathrm{~m}^{3} \mathrm{~kg}^{-1}$. The other a priori value are $F=772.3$ and $\varphi_{m}=-32.1 \mathrm{mV}$. 
The minimization of the cost function $G$ yields the following a posterior values of the

463

464 465

466

467

468

469

470

471

472

473

474

475

476

477

478

480

481

482

483

484

485

486

model parameters: $F=772.3$ and $\varphi_{m}=-47.0 \mathrm{mV}\left(\mathrm{R}^{2}=75.5 \%\right)$. Computed and fitted

formation factor $F$ are equal but the a posteriori value of mean electrical potential $\varphi_{m}$ presents a slight difference with the a priori value $(R E=46.9 \%)$.

\subsubsection{Diffusion of ${ }^{35} \mathrm{SO}_{4}{ }^{2-}$}

We have also simulated the ${ }^{35} \mathrm{SO}_{4}{ }^{2-}$ diffusion data through a clay-rock sample from the EST205 K100 core (Bazer-Bachi et al., 2007). As $\mathrm{SO}_{4}{ }^{2-}$ can be sorbed onto the mineral surface (Bazer-Bachi et al., 2007; Descostes et al., 2008), Bazer-Bachi et al. (2007) have performed a column test to determine the value of this parameter. They found $K_{d}=1.80 \times 10^{-5}$ $\mathrm{m}^{3} \mathrm{~kg}^{-1}$. The a priori values of formation factor and mean electrical potential are $F=717.1$ and $\varphi_{m}=-29.1 \mathrm{mV}$, respectively.

The minimization of the cost function $G$ yields the following a posteriori values: $F=718.3, \varphi_{m}=-29.2 \mathrm{mV}$, and $K_{d}=1.60 \times 10^{-5} \mathrm{~m}^{3} \mathrm{~kg}^{-1}\left(R^{2}=46.9 \%\right)$ (Figure 11). The strong dispersion of the experimental data yields a low $R^{2}$ fit value. However, the fitted and computed formation factors $F$ are very close to each other $(R E=0.2 \%)$. The same applies for the mean electrical potential $(R E=0.3 \%)$. The fitted $K_{d}$ is also pretty close from the value resulting from the column experiment $(R E=12.5 \%)$.

\subsection{Field Data}

In a recent study, Descostes et al. (2008) determined the diffusion coefficients of several anions $\left(\mathrm{Cl}^{-}, \mathrm{I}^{-}, \mathrm{SO}_{4}{ }^{2-}\right.$, and $\left.\mathrm{SeO}_{3}{ }^{-}\right)$in a set of the Callovo-Oxfordian clay-rock samples formation and in the Oxfordian limestones which is formation lying just above the Cox 
487 formation in the Paris Basin. From the top of the Oxfordian formation to $399 \mathrm{~m}$ deep, the 488 formation is composed by several calcareous facies (called C3b, L1a, L1b, L2a, L2b, L2c) with 80 to $95 \%$ of carbonates (ANDRA, 2005). Then, between 399 and $417 \mathrm{~m}$ deep, the Oxfordian present important vertical mineralogy variations (facies C3a). The carbonate 491 fraction decreases roughly from $80 \%$ (399 m deep) to less than $40 \%$ (417 m deep) while the 492 clay fraction increase from $15 \%$ to $45 \%$ (illite, mica and interstratified illite/smectite). The 493 rest contains principally by quartz. The upper part the COx formation (facies C2d, 417-437 m 494 deep) presents important spatial variations of mineralogy in the same oreder of magnitude 495 than C3a. Then below $437 \mathrm{~m}$ deep, the COx become more homogeneous with 40 to $50 \%$ of 496 clay minerals, $20-35 \%$ of carbonates and $35-25 \%$ of quartz (facies C2b1, C2b2, and C2c)

497 (ANDRA, 2005).

498 The measurements of the diffusion coefficients were performed with the through499 diffusion technique using a collection of core samples at depths from $166 \mathrm{~m}$ to $477 \mathrm{~m}$. For 500 each sample where anionic diffusion was made, except for $\mathrm{SeO}_{3}^{-}$, the $\mathrm{HTO}$ diffusion 501 coefficient was also measured. We use first the HTO diffusion coefficients to determine the 502 values of the formation factor $F=D_{H T O}^{f} / D_{H T O}$ (see Figure 7b). Then, using Eq. (23), we 503 determine the mean electrical potential $\varphi_{m}$ from $F$ and $D_{i}$ :

$$
\varphi_{m}=-\frac{k_{B} T}{q_{i}} \log \left(\frac{D_{i} F}{D_{i}^{f}}\right) .
$$

Figure 12 shows the values of $F$ and $\varphi_{m}$ as a function of depth. The calculated formation factor in the upper part of the Oxfordian limestone formation is quite low (from 177 to $360 \mathrm{~m}$ deep), then it becomes more important and reach $10^{3}$ between 400 and $425 \mathrm{~m}$ just

508 above the Callovo-Oxfordian argillites. The C3a layer has been particularly studied by 509 Descostes et al. (2008) with six samples between 399 and $417 \mathrm{~m}$ deep. In the middle of the 510 COx formation, $F$ is comprised between 40 and 140, which is consistent with the electrical 
511 conductivity measurements presented by Revil et al. (2005) and performed at different 512 salinities with $\mathrm{NaCl}$ brines.

513 The values of $\varphi_{m}$ are very low in the Oxfordian limestone formation. In this formation,

514 we have,

$$
\lim _{\varphi_{m} \rightarrow 0} D_{i} / D_{i}^{f}=1 / F
$$

516 which means that the electrostatic constrictivity $\delta_{e l}$ is equal to one. The C3a layer (399 to

$517417 \mathrm{~m}$ deep) presents more important values of the mean potential in the microporosity $\varphi_{m}$.

518 The values of $\varphi_{m}$ are in the range between $-40 \mathrm{mV}$ to $-20 \mathrm{mV}$.

519 In the COx formation, the calculated mean electrical potential is comprised between -

$52056 \mathrm{mV}$ and $-23 \mathrm{mV}$. Considering the experimental uncertainties and the local variation of

521 parameters $\left(\phi\right.$, CEC) between two samples, the computed $\varphi_{m}$ are quite consistent with the

522 average of computed electrical potential: $-40.7 \mathrm{mV}$ in the $\mathrm{COx}$. This electrical potential value

523 appears to be stronger than the model predictions by Eqs. (13)-(16).

$524 \quad$ Our tracer diffusion model is directly related to the generalised transport model in 525 microporous media described by Revil and Linde (2006). That implies that parameters like the 526 electrical factor $F$ and the mean electrical potential in the diffuse layer $\varphi_{m}$, can be applied to 527 determine some other rock properties. The osmotic pressure in a medium is one of them. 528 Therefore, in order to test further the range of computed $\varphi_{m}$ values, we have decided to 529 compute the value of the osmotic pressure in the COx from the diffusion test data. Revil and 530 Linde (2006) proposed the following relationship between the mean electrical potential $\varphi_{m}$ 531 and the osmotic pressures $\pi_{m}$ in a microporous medium:

$$
\pi_{m}=k_{B} T \sum_{i=1}^{Q} C_{i}\left[\exp \left(-\frac{q_{i} \varphi_{m}}{k_{B} T}\right)-1\right] .
$$

533 Considering the pore water presented in Descostes et al. (2008), it becomes possible to determine $\pi_{m}$ in the COx at several depth from the previously determined $\varphi_{m}$ by Eq. (28) and 
535 to show them on Figure 13. The predicted values can be compared to the measured fluid

536 overpressure (above the hydrostatic level) in the Callovo-Oxfordian argillites layer (see

537 Gueutin et al., 2007). The measured excess hydraulic heads are in the range 20-60 $\mathrm{m}(0.2$ to

$5380.6 \mathrm{MPa}$ ). Comparison between measured overpressure and computed osmotic pressure $\pi_{m}$ in

539 the medium are displayed on Figure 13. The computed $\varphi_{m}$ from $\mathrm{Cl}^{-}$and $\mathrm{SO}_{4}{ }^{2-}$ diffusion tests

540 (Descostes et al., 2008) are in a fairly good agreement with the measured overpressures. This

541 result will be explored further in a future work but it shows the model presented by Revil et

542 Linde (2006) can explain very different material properties inside a unified framework.

\section{CONCLUSION}

545

546

547

548

549

550

551

552

553

554

555

556

557

558

We have used a model based on a volume-average of the Nernst-Planck equation to model the diffusion of ionic tracers $\left({ }^{22} \mathrm{Na}^{+},{ }^{36} \mathrm{Cl}^{-},{ }^{35} \mathrm{SO}_{4}{ }^{2-}\right)$ through the Callovo-Oxfordian clayrock. The model developed by Revil and Linde (2006) is used to compute the diffusion of tracers in these materials using a generalized Donnan equilibrium model and the electrical formation factor. This model is able to explain tracer diffusion experiments performed by different authors in the COx formation and to determine the profile of these parameters in the formations. In addition, the mean electrical potential allows the determination of the osmotic pressure in the medium. The next step will be to develop this model to unsaturated conditions and to connect this diffusion model to geophysical measurements of complex resistivity such as modeled recently by Leroy et al. (2008).

Acknowledgement. We thank the French National Research Council (CNRS) and the French National Agency for Radioactive Waste Management (ANDRA) (S. Altmann and D. Coelho) 
559 for their support. J. Lancelot is thanked for is support through the GDR FORPRO. The Ph.D.

560 thesis of Damien Jougnot is supported by ANDRA. A. Revil strongly thanks T. Young for his

561 support at CSM. D. Jougnot thanks A. Jardani J.C. Robinet. This paper is Contribution

562 FORPRO 2008/XXX.

563

564 Appendix A

565 In this Appendix, we estimate the influence of the activity coefficient upon the 566 diffusion of the tracers through a clay-rock. From Revil and Linde (2006), the constitutive 567 equation of the diffusion flux of a single ion is writen as:

$$
\mathbf{J}_{i}=-\frac{\bar{\sigma}_{i}}{q_{i}^{2} F} \nabla \mu_{i}
$$

with $F$, the formation factor, $q_{i}=( \pm e) z_{i}$, the charge of species i and $z_{i}$ its valence $\left(e=1.6 \times 10^{-}\right.$

${ }^{19} \mathrm{C}$ is the elementary charge), and $\bar{\sigma}_{i}=\beta_{i} \bar{C}_{i} q_{i}$ the contribution of species $\mathrm{i}$ to the overall electrical conductivity of the pore water defined from $\beta_{i}$ the ionic mobility and $\bar{C}_{i}$ the concentration of species $i$ in the pore space. The chemical potential $\mu_{i}$ is related to the ionic 573 activity $a_{i}$ by $\mu_{i}=k_{B} T \ln a_{i}$. This yields,

$$
\mathbf{J}_{i}=-\frac{k_{B} T \beta_{i} \bar{C}_{i}}{q_{i} F} \nabla \ln a_{i} .
$$

575

576

578 579
The Fick law defines the ionic flux as a function of the concentration gradient. The relationship between the activity and the concentration is $a_{i}=\gamma_{i} C_{i}$ where $\gamma_{i}$ is the activity coefficient. This yields,

$$
\nabla \ln a_{i}=\frac{\nabla\left(\gamma_{i} C_{i}\right)}{\gamma_{i} C_{i}}=\frac{\nabla C_{i}}{C_{i}}\left(1+\frac{C_{i}}{\gamma_{i}} \frac{d \gamma_{i}}{d C_{i}}\right)
$$

From (A1) to (A3), we obtain, 


$$
\mathbf{J}_{i}=-\frac{k_{B} T \beta_{i} \bar{C}_{i}}{q_{i} F C_{i}}(1+\varepsilon) \nabla C_{i},
$$

$$
\varepsilon \equiv \frac{C_{i}}{\gamma_{i}} \frac{d \gamma_{i}}{d C_{i}}=C_{i} \frac{d \ln \gamma_{i}}{d C_{i}}
$$

582 where $\varepsilon$ is a correction term. For a ionic strength $I$ lower than $0.5 \mathrm{~mol} \mathrm{~L}^{-1}, \gamma_{i}$ can be computed 583 by the Davies equation:

$$
\log _{10} \gamma_{i}=-\frac{1}{2} z_{i}^{2}\left(\frac{\sqrt{I}}{1+\sqrt{I}}-0.3 I\right) .
$$

585

586

587

588

590

591

592

$$
\varepsilon=-\frac{\ln 10}{4} z_{i}{ }^{4} C_{i}\left[\frac{1}{2 \sqrt{I}(1+\sqrt{I})^{2}}-0.3\right]
$$

593 The correction term $(1+\varepsilon)$ in Eq. (A5) is always negligible $\varepsilon<<1$ when the ionic strength is

594 close to $0.1 \mathrm{~mol} \mathrm{~L}^{-1}$ and bigger. Neglecting the term $\varepsilon$, Eq. (A3) yields an apparent Fick's law,

$$
\mathbf{J}_{i}=-\frac{\beta_{i} \bar{C}_{i} k_{B} T}{q_{i} C_{i} F} \nabla C_{i}
$$


597

598

599

600

601

602

603

604

605

606

607

608

609

610

611

612

613

614

615

616

617

618

619

620

621

622

623

624

\section{References}

ANDRA (2005) Dossier 2005 argile-Référentiel du site Meuse/Haute-Marne, International report ANDRA n ${ }^{\circ}$ C.RP.ADS.04.0022.

Appelo C.A.J., Wersin P. (2007) Multicomponent diffusion modeling in clay systems with application to the diffusion of Tritium, Iodide, and Sodium in Opalinus Clay. Environ. Sci. Technol. 41, $5002-5007$.

Archie G.E. (1942) The electrical resistivity log as an aid in determining some reservoir characteristics. Trans. AIME 146, 54-62.

Avena M.J., De Pauli C.P. (1998) Proton adsorption and electrokinetics of an Argentinean montmorillonite. J. Colloid Interface Sci. 202, 195-204.

Bazer-Bachi F., Tevissen E., Descostes M., Grenut B., Meier P., Simonnot M.-O., Sardin M. (2005) Characterization of iodide retention on Callovo-Oxfordian argillites and its influence on iodide migration. Phys. Chem. Earth 31, 517-522.

Bazer-Bachi F., Descostes M., Tevissen E., Meier P., Grenut B., Simonnot M.-O., Sardin M. (2007) Characterization of sulphate sorption on Callovo-Oxfordian argillites by batch, column and through-diffusion experiments. Phys. Chem. Earth 32, 552-558.

Bernabé Y., Revil A. (1995) Pore-scale heterogeneity, energy dissipation and the transport properties of rocks. Geophys. Res. Lett. 22(12), 1529-1552.

Bourg I.C., Bourg A.C.M., Sposito G. (2003) Modeling diffusion and adsorption in compacted bentonite: a critical review. J. Contam. Hydrol. 61, 293-302.

Bourg I.C. (2004) Caractérisation du comportement d'une bentonite sodique pour l'isolement des déchets : Transport diffusif des traceurs ioniques $(\mathrm{Na}+, \mathrm{Sr} 2+, \mathrm{Cs}+$ et $\mathrm{Cl}-)$ dans la bentonite sodique compactée saturée, et titration acide-base de la montmorillonite. Ph.D. thesis, Université de Pau et des Pays d'Adour, Pau.

Bourg I.C., Sposito G., Bourg A.C.M. (2006) Tracer diffusion in compacted, water-saturated bentonite. Clays and Clay Minerals 54, 363-374.

Caceci M., Cacheris W.P. (1984) Fitting curves to data. The simplex algorithm is the answer. Byte 9, 340-362. 
625 Chatterji S. (2004) Ionic diffusion through thick matrices of charged particles. J. Colloid $626 \quad$ Interface Sci. 269, 186-191.

627 Descostes M., Blin V., Bazer-Bachi F., Meier P., Grenut B., Radwan J., Schlegel M.L., 628 Buschaert S., Coelho D., Tevissen E. (2008) Diffusion of anionic species in Callovo629 Oxfordian argillites and Oxfordian limestones (Meuse/Haute-Marne, France). Appl. $630 \quad$ Geochem. 23, 655-677.

631 Eriksen T.E., Jansson M., Molera M. (1999) Sorption effects on cation diffusion in compacted 632 bentonite. Eng. Geol. 54, 231-236.

633 Escoffier S., Homand F., Giraud A. (2000) Perméabilité et coefficient de Biot des argilites de 634 MHM, in Recherches pour le Stockage des Déchets Radioactifs à Haute Activité et à Vie 635 Longue, Bilan des Etudes et Travaux 2000 (eds. The French Nuclear Waste Agency) 206636216.

637 Gasc-Barbier M., Chanchole S., Bérest P. (2004) Creep behavior of Bure clayey rock. Appl. $638 \quad$ Clay Sci. 26, 449-458.

639 Gaucher E., Robelin C., Matray J.M., Negrel G., Gros Y., Heitz J.F., Vinsot A., Rebours H., 640 Cassabagnere A., Bouchet A. (2004) ANDRA underground research laboratory: 641 interpretation of the mineralogical and geochemical data acquired in the Callovo642 Oxfordian Formation by investigative drilling. Phys. Chem. Earth 29, 55-77.

643 Gaucher E., Blanc P., Barot F., Braibant G., Buschaert S., Crouzet C., Gautier A., Girard J.P., 644 Jacquot E., Lassin A., Negrel G., Tournassat C., Vinsot A., Altmann S. (2006) Modeling 645 the porewater chemistry of the Callovo-Oxfordian formation at a regional scale. $C . R$. 646 Geosciences 338 (12-13), 917-930.

647 Gonçalvès J., Rousseau-Gueutin P., Revil A. (2007) Introducing interacting diffuse layers in 648 TLM calculations: A reappraisal of the influence of the pore size on the swelling pressure 649 and the osmotic efficiency of compacted bentonites. J. Colloid Interface Sci. 316, 92-99.

650 Gueutin P., Altmann S., Gonçalvès J., Cosenza P., Violette S. (2007) Osmotic interpretation 651 of overpressures from monovalent based triple layer model, in the Callovo-Oxfordian at 652 the Bure site. Phys. Chem. Earth 32, 434-440. 
653 Hunter R.J. (1981). Zeta Potential in Colloid Science: Principles and Applications. Academic

654 Press, New York.

655 Jacquot E. (2002) Composition des eaux interstitielles des argilites du Callovo-Oxfordien non

656 perturbées: état de la modélisation à Juillet 2002. ANDRA Report D NT ASTR 02-041.

657 Kim H., Suk T., Park S., Lee C. (1993) Diffusivities for ions through compacted Na-bentonite

658 with varying dry bulk density. Waste Manag. 13, 303-308.

659 Crank. J. (1970) The Mathematics of Diffusion. Clarendon Press, Oxford.

660 Leroy P., Revil A. (2004) A triple-layer model of the surface electrochemical properties of 661 clay minerals. J. Colloid Interface Sci. 270 (2), 371-380.

662 Leroy P., Revil A., Coelho D. (2006) Diffusion of ionic species in bentonite. J. Colloid $663 \quad$ Interface Sci. 296 (1), 248-255.

664 Leroy P., Revil A., Altmann S., Tournassat C. (2007) Modeling the composition of the pore 665 water in a clay-rock geological formation (Callovo-Oxfordian, France). Geochim. et $666 \quad$ Cosmochim. Acta 71 (5), 10.1016/j.gca.2006.11.009, 1087-1097.

667 Leroy P., Revil A., Kemna A., Cosenza P., Ghorbani A. (2008) Complex conductivity of 668 water-saturated packs of glass beads. J. Colloid Interface Sci. 321, 103-117.

669 Limousin G., Gaudet J.-P., Charlet L., Szenknect S., Barthès V., Krimissa M. (2007) Sorption 670 isotherms: A review on physical bases, modeling and measurement. Appl. Geochem. 22, $671 \quad 249-275$.

672 Linde N., Jougnot D., Revil A., Matthäi S., Arora T., Renard D., Doussan C. (2007) 673 Streaming current generation in two phase flow conditions, Geophys. Res. Lett. 34, $674 \quad$ L03306, doi:10.1029/2006GL028878.

675 Malusis M.A., Shackelford C.D., Olsen H.W. (2003) Flow and transport through clay 676 membrane barriers. Eng. Geol. 70, 235-248.

677 Melkior T. (1999) Etude méthodologique de la diffusion de cations interagissants dans des 678 argiles. Ph.D. Thesis. Ecole Centrale de Paris.

679 Melkior T., Mourzagh D., Yahiaoui S., Thoby D., Alberto J.C., Brouard C., Michau N. (2004)

680 Diffusion of an alkaline fluid through clayey barriers and its effect on the diffusion 681 properties of some chemical species. Appl. Clay Sci. 26, 99-107. 
682 Melkior T., Yahiaoui S., Motellier S., Thoby D., Tevissen E. (2005) Cesium sorption and 683 diffusion in Bure mudrock samples. Appl. Clay Sci. 29, 172-186.

684 Melkior T., Yahiaoui S., Thoby D., Motellier S., Barthes V. (2007) Diffusion coefficients of 685 alkaline cations in Bure mudrock. Phys. Chem. Earth 32, 453-462.

686 Mendelson K.S., Cohen M.H. (1982) The effect of grain anisotropy on the electrical 687 properties of sedimentary rocks. Geophysics 47, 257-263.

688 Molera M., Eriksen T. (2002) Diffusion of ${ }^{22} \mathrm{Na}^{+},{ }^{85} \mathrm{Sr}^{2+},{ }^{134} \mathrm{Cs}^{+}$and ${ }^{57} \mathrm{Co}^{2+}$ in bentonite clay 689 compacted to different densities: experiments and modeling. Radiochim. Acta 90, 753$690 \quad 760$.

691 Muurinen A., Penttilä-Hiltunen P., Uusheimo K. (1988) Diffusion of chloride and uranium in 692 compacted sodium bentonite. In Scientific Basis of Nuclear waste Management XII (Eds. 693 Lutze W. and Erwing R.C.), Materials Research Society, Pittsburg, PA, 743-748.

694 Muurinen A. (1994) Diffusion of anions and cations in compacted sodium bentonite. VTT 695 Publication 168, Espoo Technical Centre, Finland.

696 Ochs M., Lothenbach B., Wanner H., Sato H., Yui M. (2001) An integrated sorption697 diffusion model for the calculation of consistent distribution and diffusion coefficients in $698 \quad$ compacted bentonite. J. Contam. Hydrol. 47, 283-296.

699 Revil A., Cathles L.M., Losh S., Nunn J.A. (1998) Electrical conductivity in shaly sands with $700 \quad$ geophysical applications. J. Geophys. Res. 103, 23,925-23,936.

701 Revil A. (1999) Ionic diffusivity, electrical conductivity, membrane and thermoelectric 702 potentials in colloids and granular porous media: A unified model. J. Colloid Interface $703 \quad$ Sci. 212, 503-522.

704 Revil, A., Hermitte, D., Spangenberg, E., Cochémé J.J. (2002) Electrical properties of 705 zeolitized volcaniclastic materials. J. Geophys. Res. 107 (B8), 2168. 706 doi:10.1029/2001JB000599.

707 Revil, A., Leroy P. (2004) Governing equations for ionic transport in porous shales. $J$. 708 Geophys. Res. 109, B03208, doi : 10.1029/2003JB002755, 2004. 
709 Revil A., Leroy P., Titov K. (2005) Characterization of transport properties of argillaceous

710 sediments. Application to the Callovo- Oxfordian Argillite. J. Geophys. Res. 110, B06202. 711 doi:10.1029/2004JB003442.

712 Revil A., Linde N. (2006) Chemico-electromechanical coupling in microporous media. $J$. 713 Colloid Interface Sci. 302, 682-694.

714 Revil A., Linde N., Cerepi A., Jougnot D., Matthäi S., Finsterle S. (2007) Electrokinetic 715 coupling in unsaturated porous media. J. Colloid Interface Sci. 313(1), 315-327, $716 \quad 10.1016 /$ j.jcis.2007.03.037.

717 Revil, A. (2007) Thermodynamics of transport of ions and water in charged and deformable 718 porous media. J. Colloid Interface Sci. 307(1), 254-264.

719 Revil A., Jougnot D. (2008), Diffusion of ions in unsaturated porous materials, J. Colloid $720 \quad$ Interface Sci. 319(1), 226-235, doi: 10.1016/j.jcis.2007.10.041.

721 Sato H., Yui M., Yoshikawa H. (1995) Diffusion behavior for Se and Zr in sodium-bentonite. 722 Materials Research Society Symposium Proceedings 353, 269-276.

723 Soudek A., Jankhe F.M., Radke C.J. (1983) Ion exchange equilibria and diffusion in 724 engeneered backfill. NUREG CP-0052, Proceedings of the US Nuclear Regulatory 725 Comission. NUREG, Washington, D.C.. 171-203.

726 Tikhonov, A. N. (1963) Resolution of ill-posed problems and the regularization method (in 727 Russian), Dokl. Akad. Nauk SSSR, 151, 501-504.

728 Van Brakel J., Heertjes P.M. (1974) Analysis of diffusion in macroporous media in terms of a 729 porosity, a tortuosity, and a constrictivity factor. Int. J. Heat Mass Transfer 17, 1093$730 \quad 1103$. 
732 Table 1. Physical and chemical characteristics of the through-diffusion samples

\begin{tabular}{ccc}
\hline & HTM102 (-464m) & EST205 K100 \\
\hline Porosity, $\phi[-]$ & 0.15 & $0.030 / 0.037^{\mathrm{a}}$ \\
Grain density, $\rho_{g}\left[\mathrm{~kg} \mathrm{~m}^{-3}\right]$ & 2670 & $2700^{\mathrm{b}}$ \\
Cation exchange capacity & $0.18 \pm 0.04^{\mathrm{c}}$ & $0.111 \pm 0.03^{\mathrm{d}}$ \\
CEC $\left[\mathrm{meq} \mathrm{g}^{-1}\right]$ & & \\
Temperature, $T[\mathrm{~K}]$ & $296.15\left(23^{\circ} \mathrm{C}\right)$ & $294.15\left(21^{\circ} \mathrm{C}\right)$ \\
Depth $[\mathrm{m}]$ & 464 & 424 \\
Lithofacies & $\mathrm{C} 2 \mathrm{~b} 2$ & $\mathrm{C} 2 \mathrm{~d}$
\end{tabular}

733 (a) HTO apparent porosity for tracer ${ }^{36} \mathrm{Cl}^{-} /{ }^{35} \mathrm{SO}_{4}{ }^{2-}$ disk respectively

734 (b) Leroy et al. (2007)

735 (c) Gaucher et al. (2004), Leroy et al. (2007)

736 (d) ANDRA (2005)

737

738

739

740

741

742

743

744

745 
746 Table 2. Ionic compositions of the synthetic ground water

\begin{tabular}{lcc}
\hline & \multicolumn{2}{c}{ Concentration $\left[\mathrm{mol} \mathrm{L}^{-1}\right]$} \\
\cline { 2 - 3 } $\mathrm{Na}^{+}$ & $3.44 \times 10^{-2}$ & Mazer-Bachi et al. $(2007)^{a}$ \\
$\mathrm{~K}^{+}$ & $1.34 \times 10^{-4}$ & $5.17 \times 10^{-2}$ \\
$\mathrm{Ca}^{2+}$ & $2.87 \times 10^{-3}$ & $9.74 \times 10^{-3}$ \\
$\mathrm{Mg}^{2+}$ & $5.26 \times 10^{-3}$ & $7.68 \times 10^{-3}$ \\
$\mathrm{Cl}^{-}$ & $5.00 \times 10^{-2}$ & $7.19 \times 10^{-2}$ \\
$\mathrm{SO}_{4}{ }^{2-}$ & $7.00 \times 10^{-5}$ & $4.40 \times 10^{-3}$ \\
$\mathrm{HCO}^{3-}$ & $6.20 \times 10^{-4}$ & $1.44 \times 10^{-3}$ \\
$\mathrm{I}^{(b)}$ & $5.70 \times 10^{-2}$ & $1.03 \times 10^{-1}$ \\
$\mathrm{pH}^{2}$ & 8.0 & 7.2 \\
(a) from Jacquot $(2002)$ & \\
(b) Ionic strength &
\end{tabular}

749

750 Table 3. Computed a priori parameters for tracer diffusion simulation

\begin{tabular}{cccccc}
\hline & & Porosity, & Formation & Electrical mean & Distribution \\
& Tracer & $\phi_{[-]}$ & factor, & potential, $\varphi_{m}[\mathrm{~V}]$ & coefficient, $K_{d}$ \\
& & & $F[-]$ & & {$\left[\mathrm{m}^{3} \mathrm{~kg}^{-1}\right]$} \\
\hline HTM102 (-464m) & ${ }^{22} \mathrm{Na}^{+}$ & 0.150 & 89.6 & $-23.2 \times 10^{-3}$ & $0.41 \times 10^{-3 \mathrm{a}}$ \\
& ${ }^{36} \mathrm{Cl}^{-}$ & $0.030^{\mathrm{b}}$ & 772.3 & $-32.1 \times 10^{-3}$ & 0 \\
EST205 K100 & ${ }^{35} \mathrm{SO}_{4}{ }^{2-}$ & $0.037^{\mathrm{b}}$ & 717.1 & $-29.1 \times 10^{-3}$ & $0.018 \times 10^{-3 \mathrm{c}}$ \\
& & & &
\end{tabular}

(a) Measured by batch experiment by Melkior et al. (2007)

752

(b) Apparent porosity from HTO diffusion

753

(c) Measured by column experiment by Bazer-Bachi et al. (2007) 
755 Figure 1. Picture of a COx sample by scanning electron microscopy (credit: J.C. Robinet).

756 The silica and carbonate grains are embedded into a clay matrix.

757

758

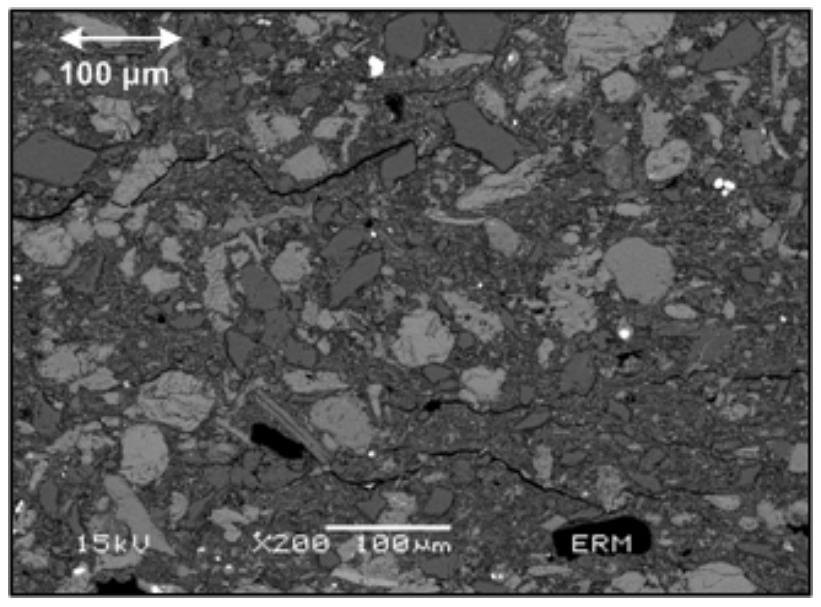

759

760 
761 Figure 2. A charged porous material: the Callovo-Oxfordian clay-rock. (a) Sketch of the COx

762 at a micro scale. This medium comprises a macroporosity space around grains (e.g. carbonates

763 and quartz) isolated by microporosity induced by clay minerals. (b) Sketch of the electrical 764 triple layer extending from the surface of the clay minerals to the center of the pore. $\mathrm{M}^{+}$ 765 represents metal cations and $\mathrm{A}^{-}$the anions.

766

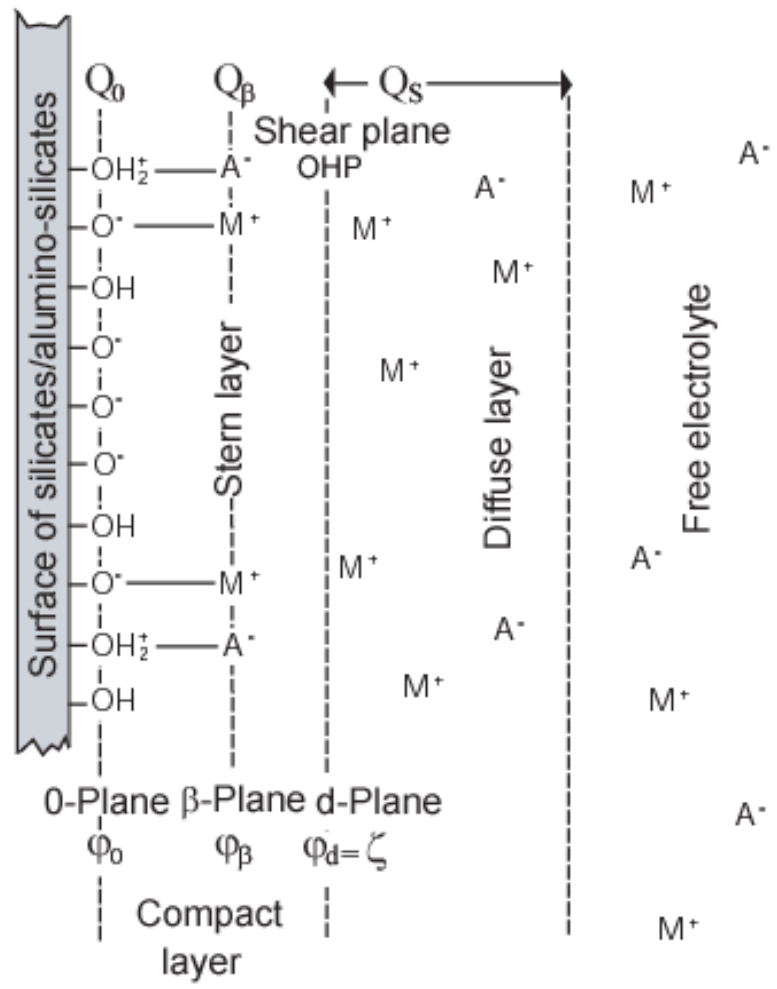


773 Figure 3. Implementation sketch of our model for tracer diffusion simulation. The subscripts $i$

774 and $T$ refer for the considered ionic species and the used tracer isotope.

775

776

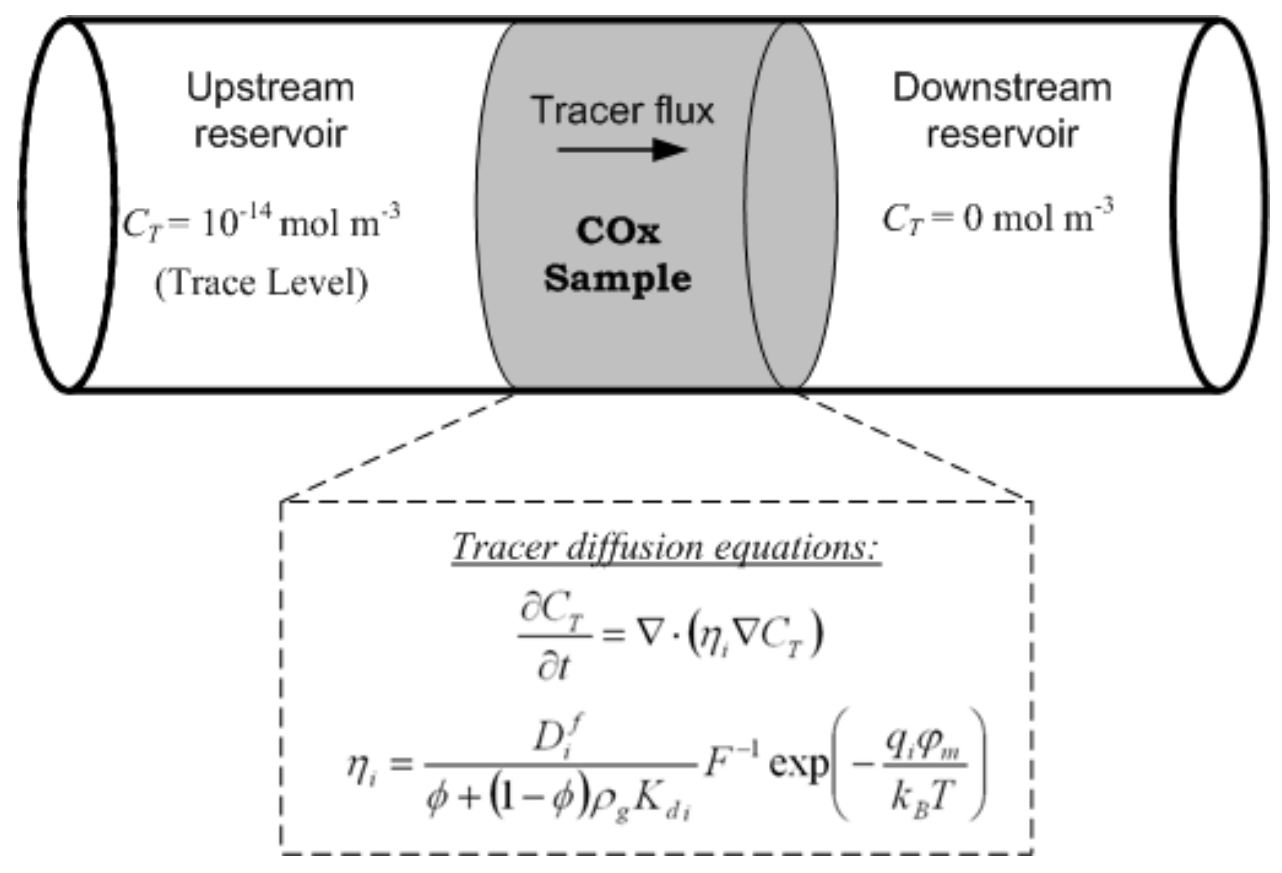

777

778 
779

780

781

782 partition coefficient $f_{Q}$ of the countercharge between the Stern and the diffuse layers, and (d.)

783 Influence of the distribution coefficient $K_{d}$. Note that in the steady-state regime, the 784 785 786

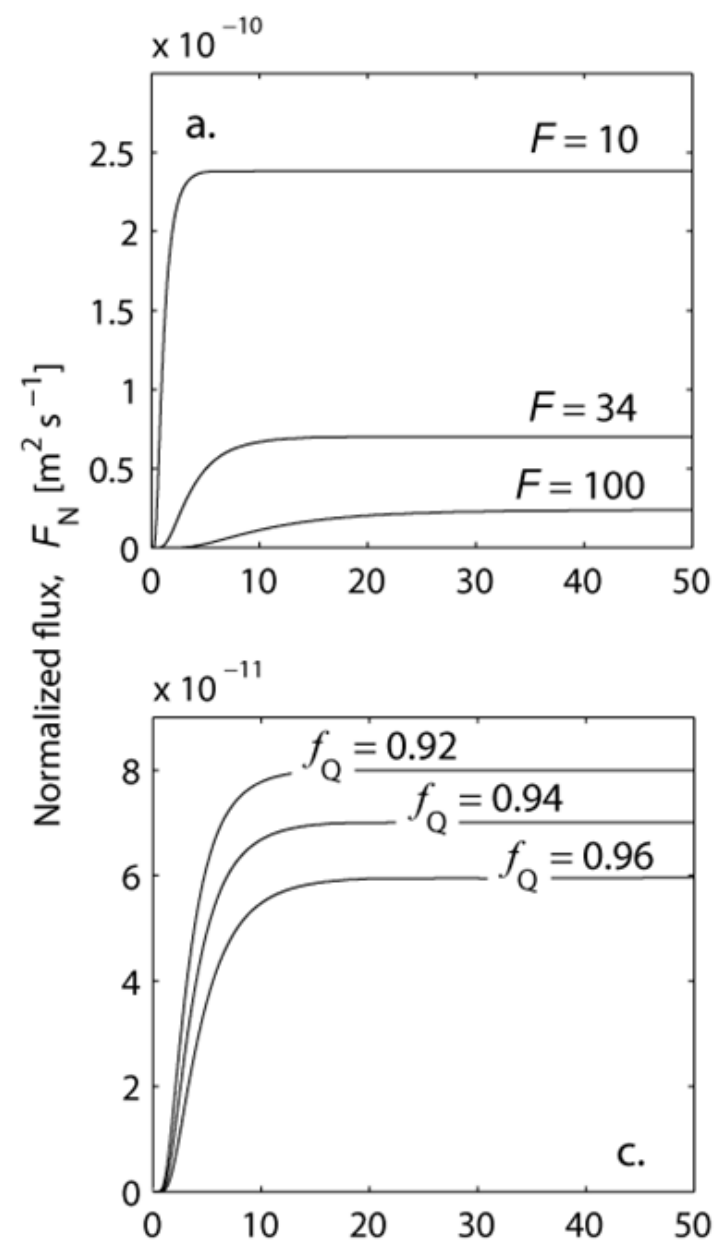

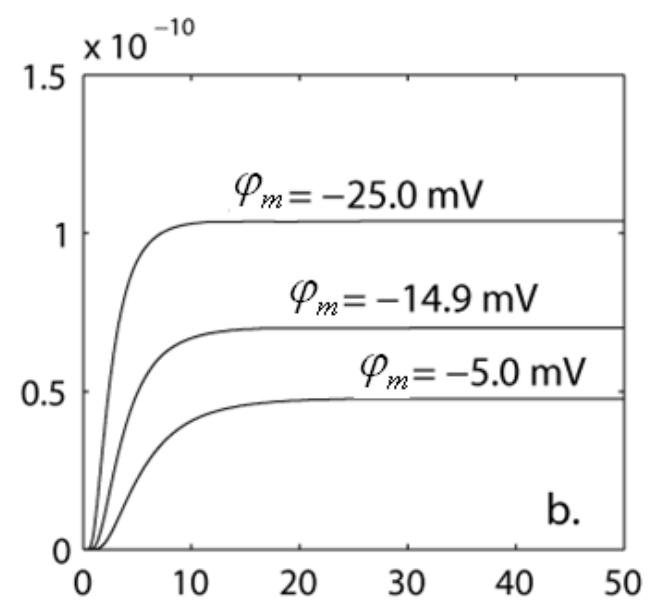

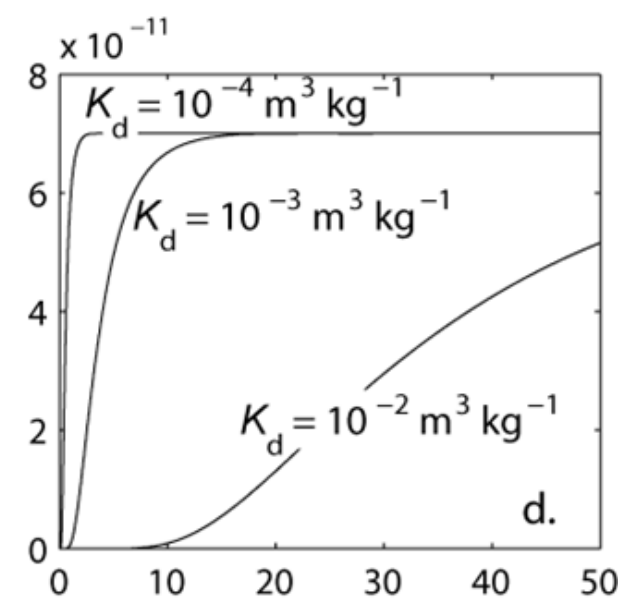


790 Figure 5. Optimization algorithm for model parameters determination from experimental 791 normalized flux. The COMSOL multiphysics ${ }^{\mathrm{TM}}$ program provides the normalized diffusion

792 flux data and the Simplex algorithm minimize a cost function $G$ to fit of these data, and then 793 determine the best value of the formation factor, the mean electrical potential in the 794 microporosity, and the partition coefficient for sorption.

795

796

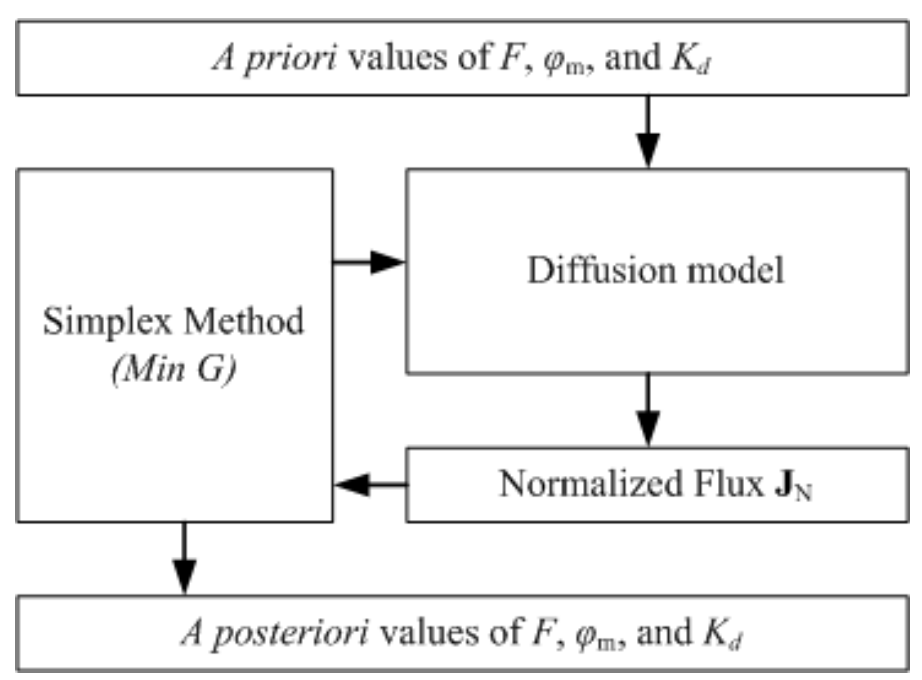

797

798 
799 Figure 6. Shape of the logarithm of the cost function with a regularization term for the 800 optimization of the ${ }^{22} \mathrm{Na}^{+}$diffusion experiment (HTM102 -464 m). The cost function $G$ has a 801 unique minimum corresponding to the position of the filled circle.

802

803

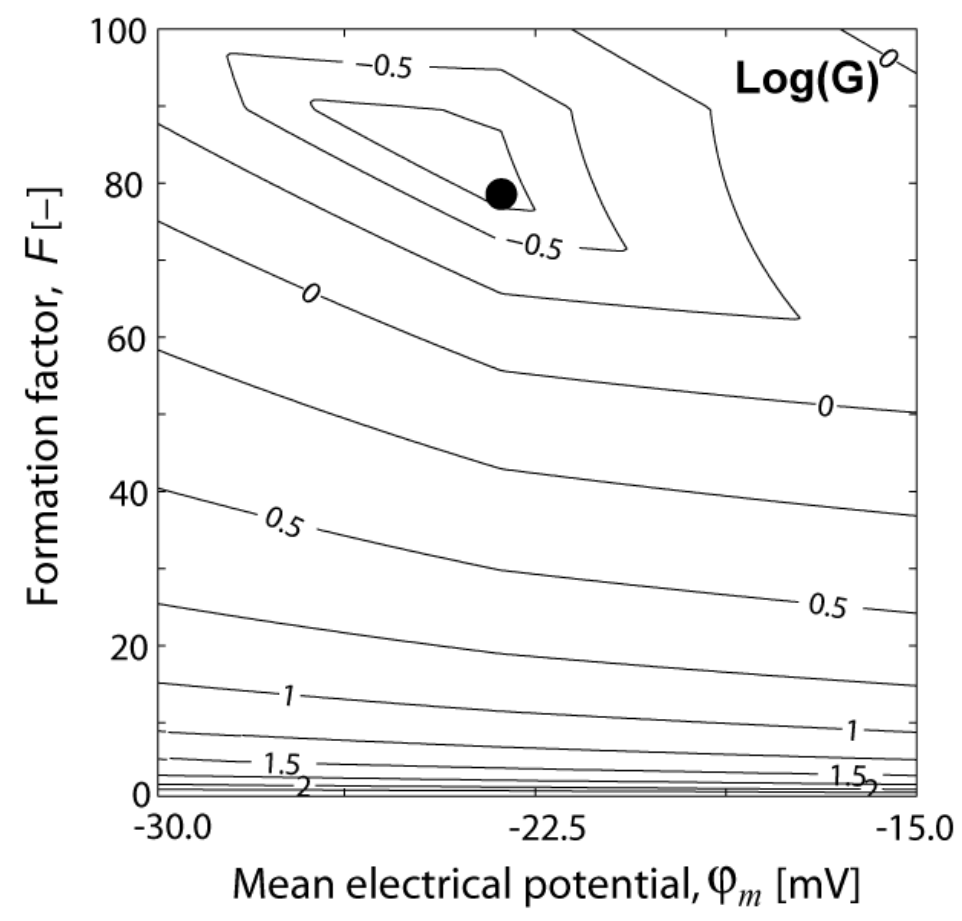

804

805 
806 Figure 7. Formation factor versus porosity in the $\mathrm{COx}$ argillite. The formation factor data

807 have been obtained: (a) by electrical measurement for Revil et al. (2005), (b) by the ratio

$808 F=D_{H T O}^{f} / D_{\text {HTO }}$ for Descostes et al. (2008), and by fit for HTM102-464 and EST205-K100

809 in the present study (a posteriori value). Archie's law for $m=1.95$ and $m=3$ have been

810 proposed by Revil et al. (2005) and Descostes et al. (2008), respectively (Oxf stand for

811 Oxfordian).
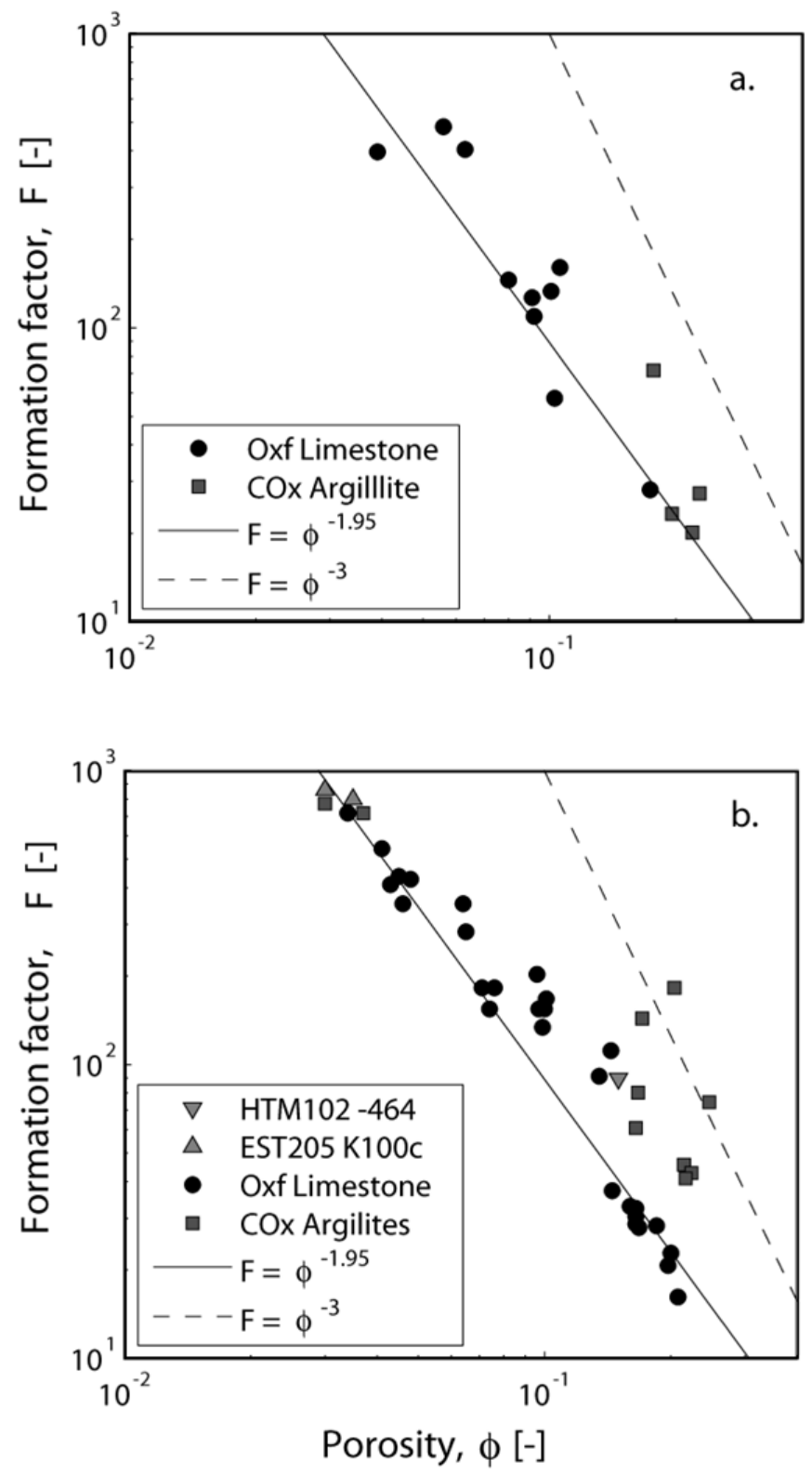

813 
814 Figure 8. Fitted mean electrical potential in the three samples and model's prediction versus

815 porosity. The mean electrical potential models are computed from the pore water chemistry

816 used for the diffusion experiments in Melkior et al. (2007) (solid line), and in Bazer-Bachi et

817 al. (2007) (dashed line). The data represent the best fit of experimental data of Melkior et al.

818 (2007) and Bazer-Bachi et al. (2007) are obtained by the algorithm presented in Figure 6 on

819 the experimental set of data (a posteriori values).

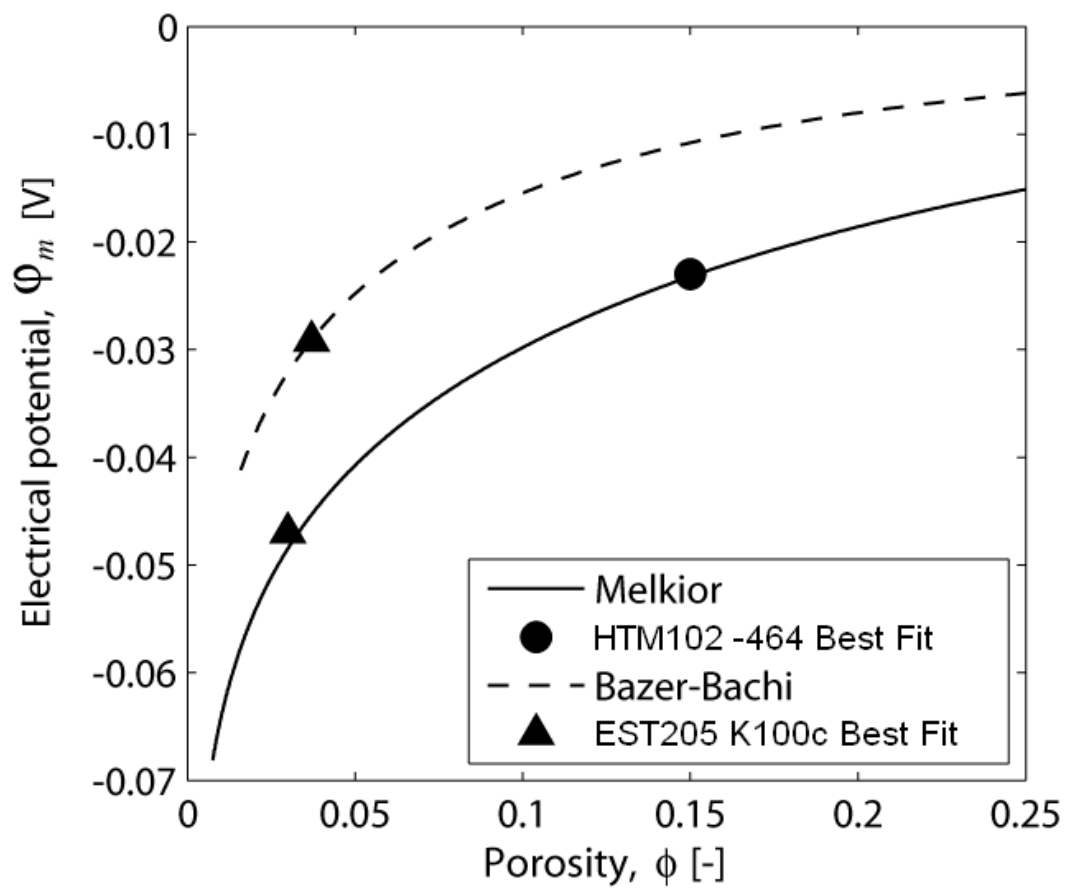

821

822 
823 Figure 9. Simulation of $\mathrm{a}^{22} \mathrm{Na}^{+}$tracer diffusion in COx (HTM102 $-464 \mathrm{~m}$ deep).

824

825

826

827

828

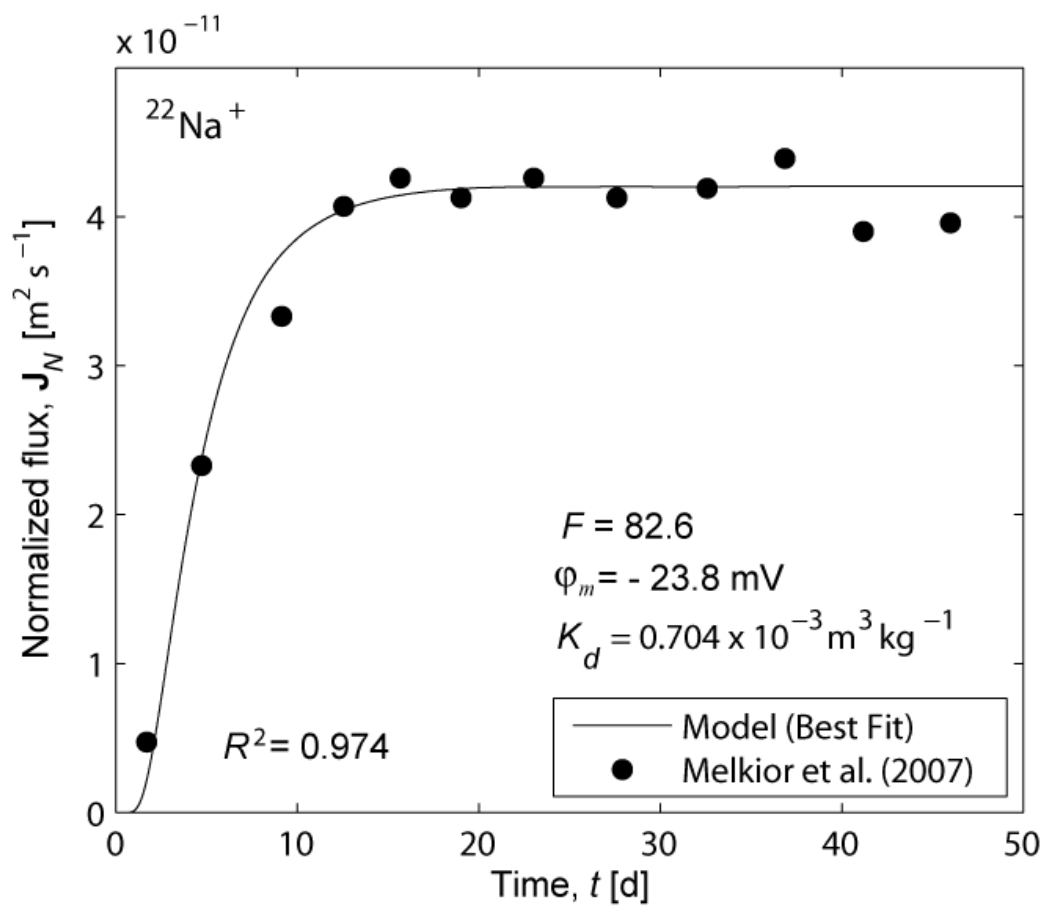


829 Figure 10. Simulation of a ${ }^{36} \mathrm{Cl}^{-}$tracer diffusion in COx (EST205 K100).

830

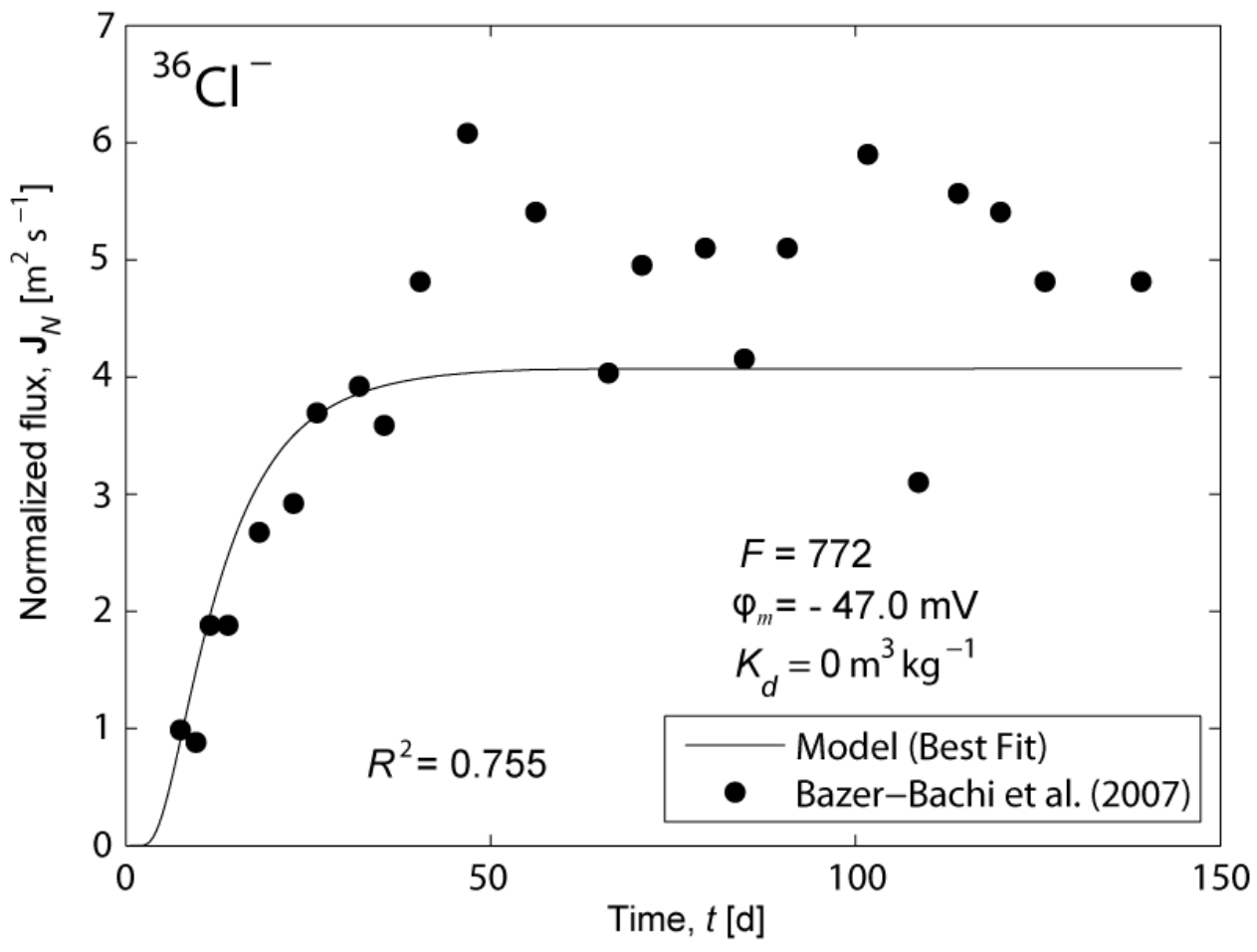

832 
834 Figure 11. Simulation of a ${ }^{35} \mathrm{SO}_{4}{ }^{2-}$ tracer diffusion in COx (EST205 K100).

835

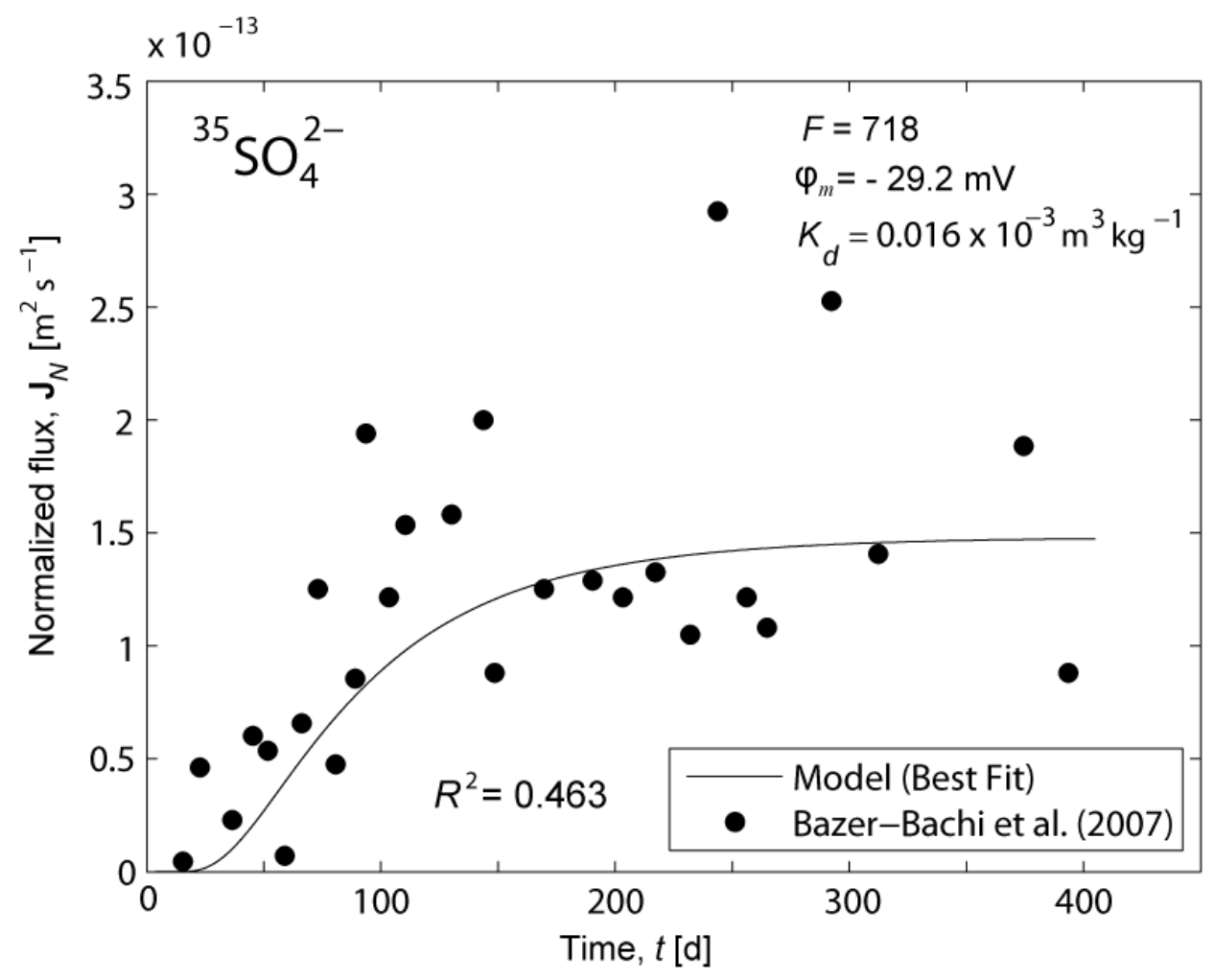

837 
838 Figure 12. Computation of $F(\mathrm{a})$ and $\varphi_{m}$ (b) in the Bure site as a function of the depth from

839 Descostes et al. (2008) experimental data. Samples have been collected in the well EST-205.

840 This borehole cross the formation of Oxfordian limestones (160-417 m below ground level)

841 and the Callovo-Oxfordian argillites (417-550 m).

842
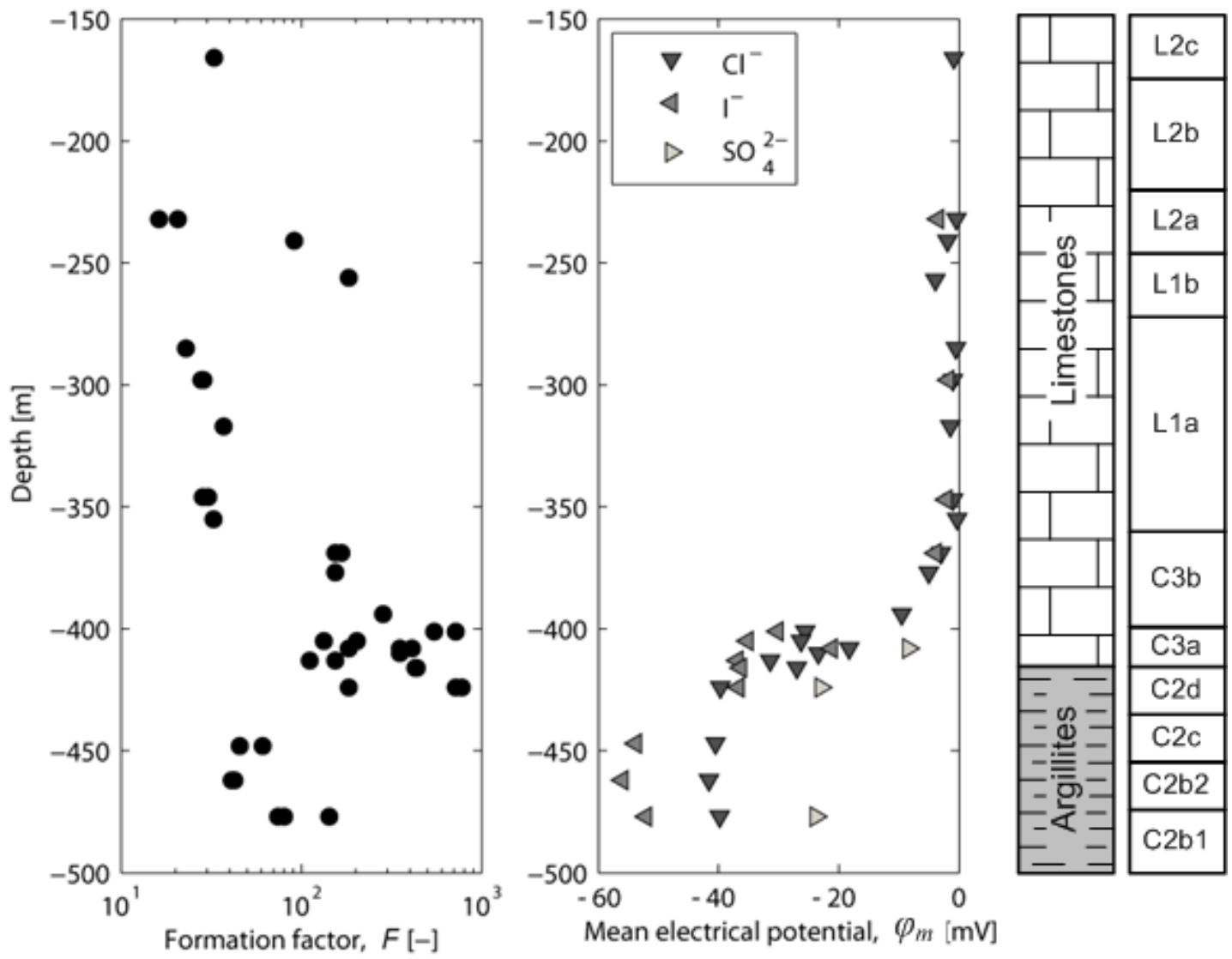

843

844

845 
846 Figure 13. Comparison between the osmotic head $\pi_{m}$ in the Oxfordian Limestones and

847 Callovo-Oxfordian Argillites and the measurements of the excess pore fluid pressure head 848 (above hydrostatic).The values of $\pi_{m}$ have been determined from the values of $\varphi_{m}$ (Figure 13) 849 and synthetic pore water described in Descostes et al. (2008). The overpressure data $(+)($ here 850 expressed in hydraulic head above hydrostatic) come from ANDRA (Gueutin et al., 2007).

851

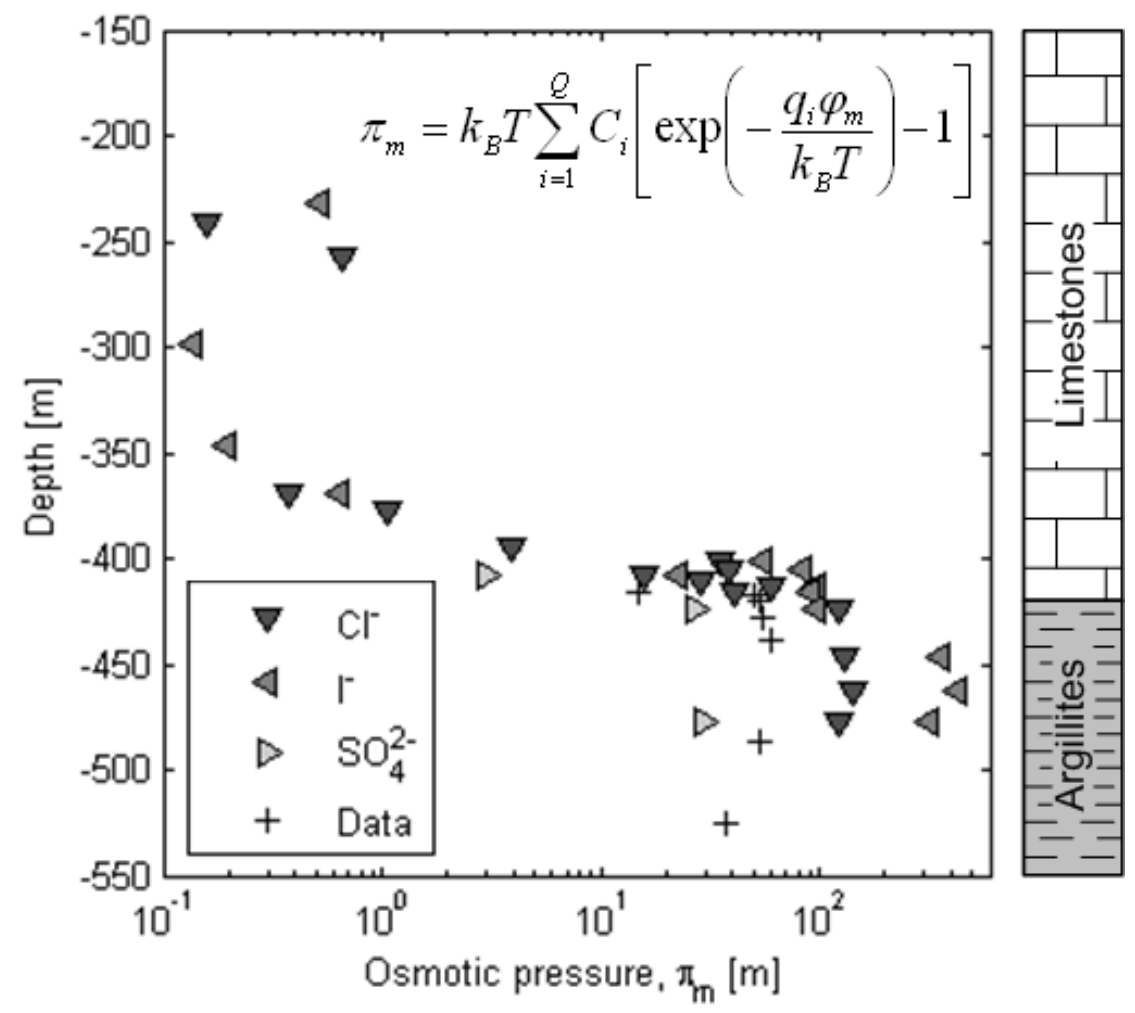

852 